\title{
Finality revived: powers and intentionality
}

\author{
David S. Oderberg ${ }^{1}[$
}

Received: 24 June 2015 / Accepted: 19 February 2016 / Published online: 10 March 2016

(C) The Author(s) 2016. This article is published with open access at Springerlink.com

\begin{abstract}
Proponents of physical intentionality argue that the classic hallmarks of intentionality highlighted by Brentano are also found in purely physical powers. Critics worry that this idea is metaphysically obscure at best, and at worst leads to panpsychism or animism. I examine the debate in detail, finding both confusion and illumination in the physical intentionalist thesis. Analysing a number of the canonical features of intentionality, I show that they all point to one overarching phenomenon of which both the mental and the physical are kinds, namely finality. This is the finality of 'final causes', the long-discarded idea of universal action for an end to which recent proponents of physical intentionality are in fact pointing whether or not they realise it. I explain finality in terms of the concept of specific indifference, arguing that in the case of the mental, specific indifference is realised by the process of abstraction, which has no correlate in the case of physical powers. This analysis, I conclude, reveals both the strength and weakness of rational creatures such as us, as well as demystifying (albeit only partly) the way in which powers work.
\end{abstract}

Keywords Metaphysics · Powers · Intentionality $\cdot$ Final causes

\section{Introduction}

There is something mysterious about powers, and philosophers generally do not like mystery. The aversion is even greater when attempts at partial demystification-with the emphasis on partial —involve the revival of ideas long thought buried by a more enlightened, scientifically-informed view of the world. When we look at the cur-

\footnotetext{
$凶 \quad$ David S. Oderberg

d.s.oderberg@reading.ac.uk

1 Department of Philosophy, University of Reading, Reading RG6 6AA, UK
} 
rent debate over powers and intentionality, however, we see certain concepts of a 'pre-enlightened' age stubbornly poking through the undergrowth, albeit clothed in a different nomenclature. That some metaphysicians find themselves reaching back to supposedly 'outdated' ideas and ways of thinking in order to clear some of the fog surrounding powers is hardly proof of their veracity. Still, the durability of these ideas among philosophers at the centre of debate about powers surely makes them worthy of serious consideration both within and outside the confines in which they are currently employed.

That non-mental powers ${ }^{1}$ are thought to share at least some, it not all, of the features of intentionality — what Franz Brentano took to be the 'mark of the mental' ${ }^{2}$ - is the striking view of a number of power theorists. ${ }^{3}$ They differ among themselves as to what conclusion is to be drawn from their observations. For Martin and Pfeifer, a distinction is still to be made between intentionality and powers, but it cannot be found in any one or combination of the classic features of intentionality championed since Brentano-by, for example, Searle and Chisholm. ${ }^{4}$ They suggest instead that the source of intentionality be located in perceptual experience-albeit they do not seem to consider the intentionality of experience itself as requiring explanation. According to Place, some of the classic features of intentionality are reducible to others and do carry over to powers, but intensionality with an 's'-referential opacity (Quine), indirect reference (Frege)—does not. This does not mean, he adds, that we have found the 'long searched for essence' distinguishing either mental from physical language or mental states from physical states, since intensionality is a feature of quotational contexts - 'what someone has said or might be expected to say'.5 Again, though, Place ignores the evident connection between quotation and mentality: only of a certain kind of creature, capable of thinking about objects in a certain way, can it be affirmed that they said or might be expected to say something. Molnar is forthright that there is such a thing as 'physical intentionality' sharing all the classic features of (mental) intentionality identified by Brentano, so he refines the picture by grounding the intentionality characteristic of rational minds in both consciousness and representation, whereas the intentionality of powers is non-conscious and non-representational. ${ }^{6}$

Needless to say, other writers are convinced that talk of 'physical intentionality', intentionality as the 'mark of the dispositional', and the like, is itself responsible for confusion bordering on incoherence. For Barker, physical intentionality is 'deeply obscure'. ${ }^{7}$ Mumford asserts what most philosophers would claim, namely that 'an understanding of certain physical properties as intentional or directed is altogether the

\footnotetext{
1 I will often speak of 'powers' without qualification, but unless context suggests otherwise I will mean any power that is not itself either mental in general or a specific mental power characterised by intentionality.

2 Brentano (1995/1874, pp. 68-69).

3 Molnar (2003); Place (1996); Martin and Pfeifer (1986).

4 Searle (1983); Chisholm (1967).

5 Place (1996, pp. 112-113).

6 Molnar (2003, Chap. 3); see p. 81 for the refined picture and a summary of his position.

7 Barker (2013, p. 649).
} 
wrong sort of image that we need for the physical world. ${ }^{, 8}$ Armstrong, considering that the introduction of intentionality into the physical fabric of the universe would endow it with some 'strange, and, it may be thought, objectionable, features', 9 proposes a wholly categorical, i.e. non-dispositional or potency-free, account of the world.

This paper is a contribution to the task of partial demystification. I will examine a number of the canonical features of mental intentionality ${ }^{10}$ - the ones that have generally attracted the most attention in the debate over supposed analogies with physical powers ${ }^{11}$ — with the aim of showing that they all point to one overarching phenomenon of which both the mental and the physical are kinds, namely finality. This is the finality of 'final causes', the long-discarded idea of universal action for an end to which recent proponents of physical intentionality are in fact pointing whether or not they realise it. A proper understanding of the classic hallmarks of intentionality reveals them as being features of finality, which I will explain in terms of the concept of specific indifference. In the course of the argument, I aim to show in particular that one of the canonical features - intensionality (with an ' $s$ ') - is no more than a feature of abstraction, which is itself the fundamental characteristic of rational mentality. There is no such parallel in the world of physical powers. I will end by examining finality in more detail, arguing that the power of abstraction distinguishing rational mentality from physical powers reveals both the strength and the weakness of rational creatures. Yet although this way of resolving the debate about physical intentionality demystifies much, there is a mystery about finality itself that demands further exploration.

\section{Directedness}

When one considers intentionality, or seeks to list its hallmarks, the term 'directedness' (like 'aboutness') is usually the first that comes to mind. Brentano himself spoke of 'direction [Richtung] toward an object'. ${ }^{12}$ The very term 'intentionality' derives from the 'esse intentionale' of scholastic philosophy, ${ }^{13}$ with 'intentionale' itself arguably finding its roots in 'intendo', as in 'to aim at, reach towards', which term itself is

\footnotetext{
8 Mumford (1999, p. 217).

9 Armstrong et al. (1996, p. 16).

10 By using the term 'mental intentionality' I do not wish to presuppose, in advance of analysing the issues, that there is any other kind of intentionality. I am merely contrasting the intentionality of the mental with alleged physical intentionality. Needless to say, those who deny the latter think mental intentionality is the only kind of intentionality there is.

11 Throughout the paper I do not intend anything by the term 'physical' other than 'non-mental'. In this wholly general sense chemical and biological powers, for instance, are physical powers - the powers of bodily entities qua bodily (of a certain kind, such as mammal or molecule), even if the powers in question are those of a creature with rational mentality. By 'mental' I mean something narrower: mental powers are, for my purposes, those of rational creatures, whether human or otherwise. Needless to say, not any power of a rational creature (say, Fred's ability to lift heavy weights) counts as mental; rather, mental powers are powers of rational creatures qua rational, or insofar as they are rational.

12 Brentano (1995/1874, p. 68).

13 See, for example, Aquinas's Summa Theologica I q.56 a.2 ad 3, Aquinas (1920, p. 63) and several other places. The term 'esse intentionale' was also used by St Albert the Great in his De Anima. For a detailed survey of the term's usage in Aquinas, see Murray (1993).
} 
found in Aquinas and other scholastic thinkers. Needless to say, 'directedness', like 'intentionality' itself, is a term of art whose application is easier to recognise than to define. Even if we do not know what it ultimately involves, we know what it means to say that Albert is thinking about Napoleon, that Belinda wants a drink, and that Charlie hopes for world peace. Their thoughts, desires, and hopes are directed at certain entities, events, states of affairs, and so on. Less obscurely, but without presuming to remove the mystery of what directedness involves, we can speak of directedness to some object of thought as being the very content of the thought itself, as Brentano himself seems to suggest by speaking in the same place of 'reference to a content' [Beziehung auf einen Inhalt].

Since the alleged analogy between intentionality and how things are with powers is our main concern, it is easy to see why sceptics about physical intentionality would balk at the very idea. The directedness of thoughts must be at least partially constituted by such interconnected activities and abilities as representation, concept possession, and consciousness. Short of panpsychism, none of these is present in purely physical entities. Salt's power to dissolve in water, however we explain it, cannot involve the representation of water or possession of the concept of water, let alone consciousness. The same goes for the power of water to dissolve salt, the power of material bodies to reflect light, of particles to attract or repel each other, or of the sun to heat the earth. Hence Bird, who regards directedness as 'ill-defined' when applied to the physical, claims: 'Agency clearly shows directedness: one acts or strives to bring something about, but one wouldn't want to ascribe agency or striving to dispositions'. ${ }^{14}$ This sort of agential directedness requires 'a concept of what is being striven for, with a plan for attaining the object striven for'. ${ }^{15}$ Here he follows Mumford, who asks rhetorically whether a soluble substance 'strives' to be dissolved, or a fragile object 'aims' to be broken. To accept such descriptions is to take the high road to 'animism' or panpsychism. ${ }^{16}$

U.T. Place is right to insist that directedness 'in some sense' is a feature of powers and that any theory must account for it. ${ }^{17}$ Molnar too is correct that panpsychism only threatens if the sceptic begs the question against the physical intentionality thesis by assuming Brentano to be right in holding both that intentionality entails directedness and that directedness entails mentality. It is the second conjunct that the physical intentionalist denies. Still, this leaves the physical intentionalist with the undischarged obligation of saying something non-metaphorical about directedness. For if striving, aiming, planning, and so forth are not essential to directedness, and nothing else can replace them, surely the physical intentionalist is saddling power theory with a term that is pregnant with suggestiveness but devoid of content?

Let us be clear first that there is some phenomenon here that needs accounting for, and let us call it directedness for present purposes and for want of anything better. It does not apply to what are now called 'categorical' qualities, and which I will call

\footnotetext{
14 Bird (2007, p. 120).

15 Ibid, p. 121.

16 Mumford (1999, p. 221).

17 Place (1999, p. 227).
} 
'actualities' (in contrast with 'potencies' or 'potentialities'). Neither the shape nor size of an object is directed at any other event, state, or process. The same goes for arrangement of parts, symmetry, and temporal or spatial distance. Again, the directedness of a power is not like a relation, such as being to the left of or having the same colour as. (I will say more about this later.) Needless to say, the real distinction between potency and actuality that I advocate is hardly a given in contemporary metaphysics: contrast, for example, the pan-dispositionalism of Bird, at least for fundamental properties, ${ }^{18}$ with the pan-categoricalism of Armstrong. ${ }^{19}$ And there is a 'mixed' view, usually seen as an identity theory, according to which every property has the nature of both actuality and potentiality: every actuality is a potentiality and vice versa. To argue directly for a real dualism of potentiality and actuality is beyond the scope of this paper: I note, for dialectical purposes, that my positive account of directedness is consistent with pan-dispositionalism, ${ }^{20}$ though my diagnosis of the mistakes in the physical intentionalist view assumes the real distinction of act and potency. None of my account, however, is compatible with pan-categoricalism or a mixed view. Pan-categoricalism, of course, denies the very reality of powers, so explaining their directedness is not in question. The mixed view also, in my view, although officially committed to the reality of powers, is at its heart more sceptical than the power realist can countenance. ${ }^{21}$ While the pan-dispositionalist, then, should find much that is congenial in my account of directedness, I would hope also that pan-categoricalists and other sceptics about the reality of powers might see that the view they oppose is not as mystifying as they think.

That said, we need to enter significant qualifications of the thesis that actualities and potencies are really distinct kinds of property. Actualities and potencies are not metaphysically independent features of things: there is no sense in which, either synchronically or diachronically, a material substance is composed of some group of actualities and another group of potentialities. This is so even if you could list them all. Actualities entail powers and powers entail actualities: nothing material can fall without having a size; nothing material can have a shape without the power to resist certain kinds of force. No actuality fails to entail at least one power on the part of its possessor, and vice versa. This is so whether or not all powers are in some way 'grounded' in actualities. But this claim of metaphysical interdependence no more implies that actualities are powers or powers are actualities than necessarily concurrent effects of a common cause are the same effect. There is more than analogy here, since the

\footnotetext{
18 Bird (2007).

19 Armstrong et al. (1996).

20 I leave aside power monism's serious problems; see, for instance, Oderberg (2012).

21 Heil (2003) advocates a mixed view. Although he denies it, the mixed view seems to be a dual aspect theory, whereby there is only a conceptual or aspectual difference between act and potency. His worries (p. 119) derive from thinking of the aspects as themselves just further properties, albeit higher-order. But one should not think this way. Denying the real distinction between act and potency means regarding both act and potency not as properties of objects but rather as ways in which we as subjects can regard properties of objects-as having a dispositional or categorical character, depending perhaps on circumstance and conditions of observation. To be sure, Heil does not advocate this position, as his view is that every property strictly possesses both a categorical and a dispositional nature. Since, however, this ascribes to properties strictly incompatible natures, it seems Heil must end up with something like a dual aspect view.
} 
mutual dependence of act and potency is itself a necessary consequence of being a material substance. ${ }^{22}$ More precisely, that a material substance has both actualities and potentialities derives from its generic nature as material; what those actualities and potentialities are in a particular case will depend on the complete essence of the substance concerned. $^{23}$

Why, however, suppose there to be an entailment between act and potency? They might both have a common cause in the essence of the substance yet remain merely regularly connected in virtue of that cause, rather than mutually entailing. In reply, the brief general argument for the stronger thesis of mutual entailment depends only on the assumption that material substances undergo genuine change- the venerable Aristotelian point. If substances have actualities and undergo change, they must be capable-i.e., have the potential - to undergo change. Conversely, if they have the potential to undergo change, there must be actualities they change from and to. Hence, without even needing to think of specific examples (not a difficult task), we have a relatively ${ }^{24}$ a priori argument for the strong thesis that every actuality entails some potentiality and vice versa. Note that I have not established the strong thesis that every particular actuality entails a particular potency (or vice versa). If the argument from change is sound, then every actuality the having of which an object can change from or into will entail the potentiality to undergo that change. And since all concrete objects are changeable, that they have actualities entails that they have potentialities as well (and vice versa). I would go further and assert that every actuality of a concrete material substance is changeable, though it may require that the substance cease to exist. $^{25}$ There are a number of theses in the neighbourhood which may or may not be true concerning the entailments between potentialities and actualities. My own view is that every single actuality of a concrete object entails some potentiality or other, and that there are tight connections between kinds of actuality and kinds of correlative potency. To explore this would go well beyond the present discussion; moreover, I take it largely to be an a posteriori matter what those connections are.

Unfortunately, it is this tight dependence between the actual and the potential that gives rise to systematic ambiguity in the way we speak of the qualities of things.

\footnotetext{
22 If, as hylemorphism holds, material substances are themselves resolvable into the actuality of form and potentiality of matter, there will be a fundamental act/potency distinction underlying all the others, but whether this is the effect of a further underlying (or overlying) cause is another question.

23 As I discuss later, although essentialism is congenial to the account of powers I will be giving, it is not as far as I can tell entailed by it, leaving the anti-essentialist free to construe my account in terms of mere kinds.

24 Relatively, because we have to assume both that there are material substances and that they undergo change. Although the argument from change is decisive in showing that every (changeable) actuality entails some potency and vice versa, it does not of course show which actualities entail which potencies (and vice versa). Nor could any wholly general argument demonstrate this, since it is largely an a posteriori matter, uncovered both by common observation and careful attention to empirical detail.

25 One might object: if Bessie the cow can lose her tail, then the actuality of her having a tail entails the potentiality to lose it. But she cannot change from being a cow, so the actuality of being a cow (or at least those actualities that are part of the essence of a cow) does not obviously entail any potentiality. Reply: the argument from change applies both to accidental and to substantial change. Bessie can change from being a cow, but she cannot survive such a change. Still, that she is a cow entails the potentiality to cease to fall under that substantial kind (and hence cease to exist).
} 
We can describe an object's shape without reference to any potency whatsoever, but when we say 'this piece of wood is square' we might be referring to its power to fit into some other shape (suppose we are putting down a floor) or to be worked into something else ('this will make a nice panel for a toy box'). The same goes for relations, where for example the only reason for asserting that $\mathrm{A}$ is to the left of $\mathrm{B}$ might be that $\mathrm{A}$ is more easily seen. Most of our usual interest in the actual qualities of things is conditioned by what powers those actualities confer, but that an actuality confers a power on its possessor, or that having a power entails having a certain actual quality, should not lead us to confound these fundamentally distinct kinds of characteristic.

In no way do actualities have any directedness: if possessed, an actuality needs no stimulus, and has no manifestation distinct from its possession: it is manifested by its very possession, even if it is not manifest in the sense of being easy or even possible to observe, and even if the object possessing it needs some kind of stimulus for the actuality to be observable. ${ }^{26}$ So far, so little progress, for all I have done is describe what distinguishes a power from an actuality. Yet we can go further, giving some flesh to the floating metaphors of 'directedness', 'pointing', 'aboutness' and 'what-forness' 27 beloved of physical intentionalists. Directedness is just a way of characterising part of the very essence of any object possessing a power, whether or not the power itself is essential or merely contingent to its possessor and whether or not this characterisation is explicit or implicit in a given statement of the essence. The characterisation in question is one way of understanding what the scholastic philosophers called finality - action for an end. If all objects have powers-where, both for simplicity's sake and for that of focusing on the primary case, by 'object' I mean 'material substance'-then if all powers display finality, so do all objects. Directedness itself is necessary for that finality to be the wholly general feature of objects that it is.

\section{Specific indifference}

Needless to say, talk of finality is just another way of talking about 'final causes', and we all know that these were banished from both philosophy and natural science many centuries ago. ${ }^{28}$ This is not the place to enter into general debate about whether the abolition of finality from modern science and philosophy resulted from the triumph of

\footnotetext{
26 Note that Molnar (2003, pp. 170-172), among others, regards what I consider a paradigmatic actuality such as shape to be in fact dispositional or potential in nature. It is true, as he points out, that there are some specious arguments for the idea that shape is categorical (actual) rather than dispositional, but he is far from making the case that it is dispositional. After all, if shape is dispositional, then why-like virtually every other power-is it not capable of being possessed yet unmanifested? What is the stimulus by which a square object 'manifests' its squareness? What does manifestation even mean in such a context? This is not the place to explore these questions; suffice it to say that the pan-dispositionalist case is by no means evident.

27 'What-forness' comes from Martin (2008, p. 59).

28 For a useful overview of the transition from 'ancient' to 'modern' conceptions of causality in the universe, see Osler (1996), and for more detail Burtt (1925).
} 
argument or of ideology, but as far as powers go I submit that the concept of finality both replaces metaphor with philosophical content and explains most of what needs explaining, to the extent it can be explained at all. To show this, I intend to explain finality in terms of the concept of specific indifference. Finality as specific indifference involves two components: (i) a specific range of possible manifestations of a power, and hence a specific range of possible kinds of behaviour by the object having that power; (ii) indifference with respect to the circumstances of manifestation within that range.

Specific indifference can easily be illustrated by several simple and unavoidably jejune examples, parts of which are so obvious as to seem absurd to mention-yet the obviousness pales beside the depth of the truth involved. (i) Sodium chloride has the power of dissolution in certain liquids, but in no liquid does it grow leaves or change into gold. It is specifically limited in what it can do or does in certain liquids; yet it is indifferent to the circumstances of dissolution, since this will depend on the circumstances of its introduction into the liquid. By circumstances I mean whatever is inessential, i.e. accidental, to the manifestation for which the power is specifically limited. Salt is indifferent to when and where it dissolves, whether the liquid is in a glass or a bucket, naturally occurring or artificially produced, and so on. The details, of course, depend on the kinds of entity involved and will be an empirical matter. Importantly, the difference between what is merely circumstantial and what is not can seem very fine indeed, even though the metaphysical distinction is wide. The temperature of a liquid $L$ may be circumstantial to a substance $S$ 's dissolution in $L$ whereas the amount of $L$ 's viscosity may be essential. Further, temperature may be essential for one substance as far as its solubility is concerned but merely circumstantial for another. Again, it is an a posteriori matter as to what counts as circumstantial. Note that specific indifference applies whether or not the power we are considering is relatively generic or specific; in other words, the specificity in specific indifference does not require a highly specific power. The solubility of salt is relatively generic compared to the more specific power of dissolving in water. That it dissolves in water rather than remains in its crystal state is a matter of specificity-the limited behaviour to which the power is directed. But the circumstances of its dissolution in water are a matter of indifference-when, where, how much water, how much salt, and so on.

(ii) Female mammals have the power of feeding their young, but in no such young does the feeding endow them with the power of defying gravity. Mammals are specifically limited in what they can do in nurturing their young; yet the power of nurturing is itself indifferent to when, where, and other circumstances in which mammalian young are nurtured. Again, this is a highly generic degree of specific indifference. A more specific degree is that healthy mammals, when they feed healthy young, cause the bodily development of the latter, not their degradation. But when, where, and how a given mammalian offspring develops depends on the kind of mammal and when, where, and how it is fed.

(iii) Human beings can shape their future but they cannot change their past. They are specifically limited in how they can act with respect to time but indifferent as to 
how they shape their future; this depends on where they are, what point of their future they envisage, and how they choose to act. ${ }^{29}$

The examples may be trite but the metaphysical point is not: all powers, by their very nature, are governed by specific indifference: there is a range of manifestations to which the power is restricted, but indifference within the range as to the circumstances of manifestation. ${ }^{30}$ Using slightly different terminology - to which I will return laterwe can say that powers have a certain indeterminacy in the sense of being determinable with respect to determinate modes of manifestation. The determinate manifestations of a single, determinable power demonstrate the indifference of the power to the circumstantial aspects of its manifestation, and the restriction of the manifestations to a range show the specificity of the power, in virtue of which the power's very identity is a matter of the specific range of its manifestations.

If we accept that even an omnipotent being cannot do the logically impossible, its omnipotence will also be specifically indifferent—restricted to the logically possible, but indifferent to what it actually does, where this will be dependent on free choice if the being is a free agent. To put it another way, a power to do anything whatsoever is not a power at all. All powers are circumscribed but at the same time carry a range of freedom that makes them, to a certain degree, indeterminate (a term that must be handled with care, as later discussion will show). At the risk of some distortion, it is the circumscription that is the mark of directedness; it is the indeterminacy that is the mark of potentiality. ${ }^{31}$

The concept of specific indifference focuses on a ubiquitous phenomenon found in both physical and mental powers, but as we shall see there are vital differences between these kinds of power that make it highly misleading to use specific indifference simpliciter as a foundation for the intentionality that physical intentionalists allege to be common to both the mental and the physical. First, however, we need to give some deeper metaphysical content to specific indifference: how, in concreto, is it realised in bearers of powers? Can we avoid lapsing into the sort of obscure metaphysical talk that-however much of it there may or may not really have been in late scholasticismled to the discrediting of final causality?

The scholastic philosophers took the 'principle of finality' to be central to the Aristotelian-Thomistic metaphysical edifice. The most common formulation is that every agent, insofar as it acts, acts for an end. Variations include the proposition that

\footnotetext{
29 Note: they are not necessarily indifferent to their future in the sense of not caring about it; the indifference to which I am referring is metaphysical, not psychological: there is no particular future, and no particular shaping of it, to which their power is limited (all of which has nothing to do with determinism or fatalism).

30 Note that this is not the thesis that there are so-called 'multi-track' dispositions, at least where this means dispositions with different kinds of manifestation. There is a lot of unclarity in the literature about just what it is to be 'multi-track' (Vetter 2013; Bird 2007, pp. 21-24; Molnar 2003, pp. 198-199), but having different kinds of manifestation is the most plausible meaning. Needless to say, getting a grasp on what distinguishes kinds of manifestation is crucial, but assuming a principled distinction can be made it will still be the case that single-track dispositions also display specific indifference. I will return to multi-track dispositions later.

31 The closest I have come to finding the idea of specific indifference in the literature, albeit not expressed in quite the same terms, is Mumford and Anjum's notion of a 'selection function': Mumford and Anjum (2011, pp. 185, 189-190). Mumford and Anjum's account of 'selection' and their approbatory use of 'directed' does seem to be a retreat—better, a move forward — from the view advanced in Mumford (1999), where 'directedness' is seen as halfway to animism.
} 
every nature is ordered to an end; that nature does not act in vain; that the end is the first principle of activity; and that the end is the reason for all movement. ${ }^{32}$ The idea these formulations seek to capture is that final causes-ends of action-are built into all agents, whether the agents be conscious or not. Centuries-old yet still-recycled canards about scholastics' holding that everything 'tries' to achieve some end, 'strives' for it or 'seeks' it (cf. the wilful distortion of Aristotle on objects' falling to the centre of the earth) have achieved nothing beyond the misrepresentation of intellectual history and the retardation of philosophical progress. Key for the scholastics is the idea that all activity is ordered toward ends, whether the ends be freely chosen or else built into agents in virtue of their essential constitutions. In the case of mental powers belonging to rational beings such as ourselves, this fundamental finality is mediated by the process of abstraction, as I will later explain. We will see that this fact about rational thinkers does not entail that the same, or even a similar, notion can in any way be applicable to bearers of mere physical powers. Even if we frame the distinction in terms of the much-abused word 'representation', we are hard pressed to see why intentionality as a representational notion implies anything representational in physical powers. ${ }^{33} \mathrm{We}$ can, if we like, speak of powers as having 'representations' of their manifestations, but nothing is to be gained by this Procrustean use of already-fuzzy terminology. Let us then define what a power represents as precisely the end built into it in virtue of its essence-Martin's 'what-forness'. This is the final cause of the power; better, a final cause of the power bearer.

Yet what is this final cause? In what sense is it a cause at all? Is it something that exists? It is enough for present purposes to clarify some misconceptions in order to bring final causes into focus. First, a final cause most certainly is a cause-only not an efficient cause. There is no 'fininculus' ${ }^{34}$ residing within a power bearer, somehow activated by a stimulus and thereby making the power bearer manifest its power. The idea is not only absurd, but on the theory of final causes it would generate a vicious regress. Final causes are the precondition of the very possibility of any efficient causality. If fire burns wood but not pure water, if beta particles can penetrate a sheet

\footnotetext{
32 Wuellner (1956, p. 38) and the references on p. 41 to original sources in Aristotle and Aquinas as well as to a number of scholastic writers.

33 There is no space to discuss at length the question of whether all mental intentionality involves representation. It might be thought that sensation is intentional but in no way representational. Molnar thinks that bodily sensation is a kind of non-representational intentionality (2003, pp. 74-81), thus lending support in his view to the idea of physical intentionality. It is hard to see what Molnar's argument establishes. Bodily sensation shows none of the classic Brentanian marks of mental intentionality apart from directedness which is, as I argue, no more than an aspect of finality as specific indifference. The sensation of cold, for example, is restricted to a specific range of objects (where the object is just whatever is sensed), and there is indifference within the range as to the circumstances in which that kind of sensation occurs. But that is about it, meaning that bodily sensation looks just to be a kind of physical finality (the finality of a conscious, embodied creature) rather than a phenomenon 'supporting' (Molnar 2003, p. 74) the possibility of physical intentionality. If there is any genuine mental intentionality in bodily sensation, it is exemplified by the way that a rational thinker conceptualises or represents what she feels, which thoughts are different from the sensations themselves. The sensations themselves are had by non-rational animals, and they cannot conceptualise or represent their sensations, let alone perform any abstraction on them. When animals sense, it is more like what Place calls 'inspection' (1996, p. 107): for an animal, feeling pain is like watching prey. The pure sensation, whether in the human or the animal, is merely an instance of generic finality.
}

34 'Finis' = 'end', 'purpose', by analogy with 'homunculus'. 
of paper but not a sheet of lead, this can only be because the agents are ordered to some effects rather than others: they each have their own finality, which restricts the range of their effects (while still having various kinds and degrees of indifference within the range). Remove the finality and you remove efficient causation altogether. But if this is the case, there could be no fininculi acting as efficient causes of power manifestation since they too would require a higher-order finality ordering their own efficient causal behaviour. We would then have to postulate further, higher-order fininculi, themselves explained in terms of yet more efficient causation, and so on ad infinitum. We would never arrive at an explanation of all efficient causality in terms of final causality, contra the scholastic theory. In any case, that the idea of fininculi is as unscientific as that of homunculi should be sufficient to dispel it as no more than a pejorative irrelevance.

Secondly, puzzlement over whether final causes 'exist' is generated by the very woolliness of the question. Final causes are real causes, only not efficient. So we should not expect them to be events, states, processes, or substances of any kind. If that's what existence requires, then they do not exist. But why should existence require this? Plenty of things exist that are neither events, states, processes, or substances. What about properties, or maybe property instances, which the scholastics usually called modes $?^{35}$ Final causes cannot be first-order properties, since these are the ones whose very finality scholastics take final causes to explain. Although an exploration of all the options is beyond the space available here, one plausible line of speculation is that final causes are higher-order properties of agents; we might say, for instance, that the finality of salt with respect to solubility in water is explained by a higher-order property governing salt's first-order structural and compositional properties such that salt interacts with water in a certain way. If we think of final causes in this fashion then we must not conceive of them as in any way producing the first-order properties or doing anything to salt to make it behave in the relevant way. We thus avoid the sort of regress problem generated by a finincular view of finality.

Still, we need also to think of the final cause as something like a scholastic causal principle, a metaphysical 'spring of action' from which an agent's first-order behaviour derives. The final cause governs the way the first-order properties of agents interact, whether within an agent or between agents. The first-order structural and compositional properties of salt are governed - as we are speculating - by the higher-order property of salt's being directed to dissolution in water. If we decide to step on eggshells by saying that a final cause is a reason for action, then the final cause governing salt's behaviour in water is the reason for its dissolving. This does not imply that salt has a reason for dissolving in the way that Fred has a reason for putting salt on his salad. In rational agents, reasons for action are mediated by concepts-better, by abstraction (worse, by 'representations'). The reason for salt's dissolution in water is the final cause of its behaviour: salt is governed by a higher-order property in virtue of which it behaves in water in a certain way. That higher-order property is part of the essence of salt, what scholastics - following Aristotle's fourfold theory of causation-called the 'formal cause' of salt. In other words, it just is part of the essence of salt to be

35 I use 'property' in the contemporary generic sense, whereas the scholastics distinguished between accidents in general and the more specific kind of accidents known as 'propria' or properties strictly speaking. See further Oderberg (2011). 
soluble in water: when we isolate any power or cluster of powers in virtue of which a substance behaves in a certain way, we are thereby isolating one or more final causes of the substance's behaviour.

Before considering the higher-order account further, I should allay the concern that the theory I am developing here requires natural kind essentialism, a position toward which even the most robust defenders of powers are sometimes diffident. ${ }^{36}$ On the face of it, although natural kind essentialism is not entailed by the phenomenon of specific indifference (whether understood as a higher-order property or not), it would be strange to try to combine specific indifference with an anti-essentialist position on natural kinds (or species, to use the more traditional scholastic term). For a start, if all material objects must have some power or other (which is highly plausible), then specific indifference would appear reasonably to be what we can call a generically essential feature of all material objects, given that they belong to the genus material object. Even on the higher-order view, if specific indifference is partly constitutive of certain first-order structural and compositional properties (part of their essence as the first-order properties they are), then if all material objects must have some power or other, they must have some or other of the structural and compositional properties in virtue of which the higher-order property of specific indifference is true of those objects. And we might argue by transitivity—albeit put rather loosely—-that if specific indifference is of the essence (since partly constitutive) of these generic first-order properties, and if they are of the essence of material objects, then specific indifference is of the essence of the kind material object.

Mightn't one, however, still be sceptical about whether any more specific kind of directedness was essential to any more specific kind of material object? Even if one thought that salt, qua material object, had to have some powers, one might still deny that solubility in water was essential to it; and this is a well-known matter of continued debate between dispositional essentialists and their opponents. ${ }^{37}$ I accept that my account of directedness does not conclusively settle this question: one might hold both that particular kinds of directedness were real phenomena of particular kinds of object and that they were merely accidental to those kinds. We know this to be the case for the accidental powers that even an essentialist must acknowledge (unless they espouse hyperessentialism), such as the power of sight or to lift a certain weight. Why might it not be the case for all powers? Of course, this takes us into a whole new area of analysis that goes well beyond the position I am defending here; I do not pretend that my position advances that debate significantly, a debate that is a concern for all power theorists who are natural kind essentialists. But my position at the very least lends itself to natural kind essentialism, since specific indifference, whether a higher-level property or not, looks like a feature of kinds of object that runs about as deep as any feature can, entering into the very identity of the kind-how it behaves, not merely how it is structured or composed, in other words the very kind of causal contribution

\footnotetext{
36 For instance Bird (2007, pp. 208-212) and Mumford (2004), the latter being much clearer in his rejection of natural kind essentialism. By contrast, Molnar (2003, pp. 181-184), Bird (2010), and Hawley and Bird (2011) show clear commitment to natural kind essentialism. Bird's thinking has evidently moved more explicitly in the essentialist direction.

37 See, for instance, the debate between Bird (2001) and Psillos (2002).
} 
its members make to the natural order. Indeed, if the real directedness of objects with powers does not go to the very identity of the kinds to which they belong, one begins to wonder what interest the structural and compositional properties even have, whether in terms of theory or of scientific and everyday practice. In short, a robustly realist account of directedness in terms of specific indifference cannot refute the anti-essentialists, but then it is not supposed to. If, on the other hand, one wishes selectively to maintain some form of natural kind essentialism without admitting directedness, then one must show why properties with directedness do not play the sort of role in constituting the identity of a given kind that other, principally structural and compositional, properties do. That seems to me a tall order.

In a recent discussion of some of the ways a dispositionalist/power theorist might explain directedness, Matthew Tugby considers the higher-order property view but is rather dismissive. ${ }^{38} \mathrm{He}$ accepts one of its advantages, however: like the Platonism he espouses, but with less metaphysical extravagance, the view underwrites the possibility of unmanifested powers, something all power theorists accept. On Tugby's Platonism, the unmanifested fragility of a glass - to make the point clearer, the only piece of glass that ever has been or will be-is a reality underwritten by the second-order, internal manifestation relation between the transcendent universals of (to put it very loosely) fragility and breaking. ${ }^{39}$ I will examine Tugby's Platonist theory shortly. On the higherorder view I am tentatively suggesting, by contrast, no such transcendent relation is necessary: every agent has dispositional properties that are themselves governed by a higher-order property securing the invariable, essential behaviour of the agent possessing the first-order properties. It is in virtue of the higher-order property that the first-order dispositional properties are not mere bits of accidental behaviour that agents display on occasion, but rather manifest in the way they do as an essential feature of the agent itself. Without some such specificatory and organisational principle, what we know to be necessitated, non-accidental, highly regular and predictable behaviour would not, I venture to suggest, have an explanation.

So what are Tubgy's objections to the higher-order view? The first is that 'each and every disposition has a further property: the property of having some manifestation M. ...these second-order properties are taken on this proposal to exist in addition to the manifestation properties themselves. Positing these extra second-order properties as well as the manifestation properties themselves is clearly an increase in ontological commitment. ${ }^{40}$ I will not spend too long on this objection since Tugby himself realises it 'may not strike many as conclusive', ${ }^{41}$ particularly when the quantitative metaphysical expansion on the higher-order view is compared to the relative lack of qualitative parsimony on the Platonist position. Parsimony aside, I take issue with Tugby's characterisation of the higher-order properties themselves. He thinks that the property of having manifestation $M$ is all there is to such properties, with appropriate

\footnotetext{
38 Tugby (2013, pp. 472-474).

39 Ibid, pp. 454-455. A more complete account would bring in stimulus universals as well as manifestation universals, thus linking the universal fragility to both (again speaking loosely) the universals being struck by a force and breaking. Presumably Tugby omits stimulus universals for the sake of simplicity.

40 Ibid, p. 472.

41 Ibid, p. 472.
} 
variance in the manifestation type for each disposition. This jejune way of looking at what I am considering to be final causes is calculated to make them look otiose-an ontological spare wheel. If final causes are higher-order properties, their content is not the mere specification of a manifestation type. Rather, it is the specification of a substantial principle of operation that is part of the essence of the agent. The solubility of salt itself is governed by a substantial principle of operation according to which salt, by virtue of its essence as a certain kind of compound, behaves in a specific way in water, albeit within a range of indifference as to the contingent circumstances of its dissolution. Such a property — what we might call a finality property - might not be the direct object of a natural scientist's investigation, but for the scholastic metaphysician it is the substantial precondition of the scientist's investigation of any first-order dispositional properties at all.

Tugby's second objection, on which he places greater weight, is as follows ${ }^{42}$ : 'how, we may ask, are we to understand a disposition's second-order property of having manifestation M? Since this property is distinct from the manifestation property itself, and since this property somehow enfolds within itself reference to the manifestation property, which may not itself exist if Platonism is rejected, then these second-order properties seem to display precisely the kind of Meinongian, quasi-intentional characteristics we were worried about in the first place.' What the advocate of the higher-order proposal needs, he claims, is a 'transparent account of how these second-order properties can, as non-mental entities, embody a directedness to something which may not exist. ${ }^{43}$ This objection, I submit, rather than adding a new substantive point is more a statement of incredulity coupled with an implied insistence that directedness must be a relational affair involving existing relata (on Tugby's view, Platonic universals). As against this, the higher-order theorist needs to stand their ground. The idea of specific indifference, cashed out in terms of a higher-order property governing the first-order behaviour of a power, bypasses Meinongian worries by placing directedness to a manifestation within the very essence of the power bearer. It is the anxious insistence ${ }^{44}$ that directedness must be a relation, if it is to be anything comprehensible at all, that prevents acceptance of it as constitutive of the nature of what has it. Like all critics of 'physical intentionality', Tugby worries about how non-mental power bearers can have a directedness that is supposed to be the hallmark of the mental. My contention, however, is that the supposition itself is a mistake, leading to an ontological panic that is avoidable by focusing instead on finality itself and the different ways in which it is manifested in both mental and purely physical beings. Directedness is not a relation; it is constitutive of the way in which power bearers behave in virtue of their powers. Unless the power bearer has a relational essence-in other words, is such that to be the kind of thing it is it must be in an actual relation to some other thing-then the power bearer's directedness is a wholly intrinsic affair, a matter of how it is built to operate.

\footnotetext{
42 Ibid, p. 473.

43 Ibid, p. 473.

44 Ibid, p. 460 contra Heil.
} 
Let's explore this idea a little further, examining Tugby's worries about Aristotelian dispositionalism generally, as against the Platonism he supports and to which Bird also is sympathetic. ${ }^{45}$ For Tugby, directedness is a higher-order (type-level) relation between Platonic universals. The solubility of salt, then, consists in - is identical to-a relation between the universal solubility and the universal dissolution in water ${ }^{46}$ The advantage of Platonism, he claims, is that it explains two non-negotiable platitudes about powers: (1) they can exist unmanifested; (2) they (or at least some) are intrinsic to their possessors. As to (1), even if some or all samples of salt never dissolved in water because they were never immersed in it or even because no water existed, they would all still possess solubility in water due to the guaranteed existence of the Platonic universal dissolution in water. By contrast, on an Aristotelian (immanentist) view of universals, such as I support, if no actual dissolution of salt in water ever takes place, the Aristotelian universal dissolution in water does not exist, so the higher-order relation between the solubility and dissolution universals does not exist, so salt's directedness, and hence its very power, does not exist. ${ }^{47}$ Platonism respects unmanifested powers, so the argument goes; Aristotelianism does not.

Tugby thinks, however, that the Aristotelian could bite the bullet and simply deny the existence of unmanifested powers, that is, powers that an entity of kind $K$ can possess yet which have never been manifested by any $K s .{ }^{48}$ So much for what Tugby took to be a platitude; in any case, it is a bullet that an Aristotelian should respectfully decline. For the problem lies not with Aristotelian dispositionalism as such, but with the idea that it should be explained as a relation between universals. All dispositionalists should want to say that in the envisaged (admittedly extreme) thought experiment, salt is as soluble in water as it ever was and also is when the manifestation universal does exist. If positing a higher-order relation does away with this platitude then so much for the relation, not the platitude. For Tugby, however, more important is platitude (2) — that at least some powers are intrinsic_-as far as refuting Aristotelian universals dispositionalism is concerned. For the theory entails that if external circumstances were to change - again, were there to be no dissolution in water, maybe no water at all, in the history of the world - then salt would not possess solubility in water. So salt's actual solubility in water could not be intrinsic, whereas it looks about as central an example of the platitude as any. So much, concludes Tugby, for Aristotelian universals dispositionalism.

\footnotetext{
45 Bird (2007, Chap. 3.2).

46 I keep it simple for simplicity's sake, avoiding the question of how exactly the universal solubility is to be specified, as well as general worries about Platonism as opposed to particular concerns with Platonist dispositionalism.

47 What if other dissolution-in-water events take place, not involving salt: won't the universal still exist? Shouldn't the universal be dissolution of salt in water rather than dissolution in water? Again, we have to sidestep this important question, but let's suppose no dissolution in water, of any kind by any substance, takes place.

48 Another complication to be sidestepped: does the Aristotelian universal only exist at time $t$ when it is being instantiated at $t$ ? If so, then a particular sample $S$ of salt loses the power of solubility the moment no dissolution is happening anywhere in the world. This seems absurd. Hence the Aristotelian universals dispositionalist will need to liberalise their criterion of existence for universals, perhaps employing a crosstemporal principle along the lines of Armstrong (1989, pp. 75-76).
} 
So much, I conclude, for the higher-order relation interpretation of Aristotelian universals dispositionalism. Here I side with $\mathrm{Heil}^{49}$ and other trope theorists, for whom the directedness of powers is in no way relational. On my theory, specific indifference is a wholly intrinsic affair, being the way in which to understand the directed behaviour of power bearers. That salt needs water in order to dissolve in it does not entail that there must be any water for salt to be soluble, any more than my needing sounds in order to hear entails that there must be sounds for me to have the power of hearing. So it is not the Aristotelian part of Aristotelian universals dispositionalism that Tugby's argument undermines, but the universals part understood as importing a higher-order relation into the analysis of dispositionality. To see definitively that this is so, consider what he says about intrinsicness on his preferred Platonic universals dispositionalism. The answer is-not much. He assents to Bird's rather gnomic remarks ${ }^{50}$ about not confusing the first level with the second level: directedness consists of a secondorder relation between universals, which is consistent with the intrinsic first-order possession, by an object, of a power essentially characterised by that second-order relation. In other words, it is possible for an object intrinsically to possess a property that is essentially relational. Yet if salt intrinsically possesses solubility in water, and solubility in water, as a Platonic universal, is essentially in the 'directedness' relation to the Platonic manifestation universal dissolution in water, then so is salt, at the first level, essentially in relation to the manifestation universal. So how is its possession of solubility intrinsic after all?

Well, Tugby's 'rough definition' of $x$ 's having a property intrinsically only includes 'independence of the existence of distinct particulars and $x$ 's relation to them', 51 so by that definition salt will still possess solubility intrinsically. Yet this seems to me a gerrymandered definition: why exclude relations to Platonic universals themselves, if only to avoid the undesirable extrinsicness result? The Platonist could respond: salt's relation to solubility is merely instantiation, which is a formal relation; the relation of solubility to dissolution is merely an internal relation; so salt's relation to dissolution cannot, however we characterise it, be in any way a threat to salt's intrinsic possession of solubility. This reply strikes me as suspiciously ad hoc: what kind of relation is it, then, between salt and the Platonic universal dissolution? It looks like an internal relation, to be sure, since salt necessarily has it to dissolution as long as salt is soluble (whether or not salt is necessarily soluble, moreover); but why should this internal relation not entail salt's possessing solubility extrinsically? Moreover, it is rather difficult to come up with any non-dispositional example of an object's possessing intrinsically a property that is itself relationally defined. (Consider typical examples such as parent or tall.) Maybe this is something special about dispositions, but Tugby gives us no independent reason for thinking it so.

Finally, suppose this sort of objection fails. There is another problem for Platonic universals dispositionalism, one that looks fatal. For consider: on the one hand, for salt to be soluble it must instantiate a universal that is related to the distinct universal

\footnotetext{
49 Heil (2003, Chaps. 8.4-8.6).

50 Bird (2007, pp. 140-141).

51 Tugby (2013, p. 465).
} 
dissolution. But when salt actually dissolves, it also must instantiate the universal solubility that is related to the distinct universal dissolution. So how are we to distinguish, as dispositionalists must, between manifestability and actual manifestation, i.e. between the very actuality and potentiality that mark out the dispositionalist position? The answer, of course, is for the Platonist to point out that the relation holding between the universals, whether or not any salt is actually dissolving, is the internal 'directedness' relation; but when some salt actually dissolves, the universals take on an extra, external relation, say the relation of co-instantiation. The worry, then, is that the Platonist is appealing to the very concept of directedness that he was trying to define in terms of a relation between universals. Instead of defining it in terms of the relevant relation, however, he ends up defining the relation in terms of $i t$. How is this progress? He can say that the directedness relation is just the relation of definability, or some identity-involving relation; but so does the non-relationalist. After all, on my position, solubility is of course partly defined in terms of dissolution! But I do not appeal to necessarily existing universals to explain directedness, and treat it as a wholly non-relational affair. So how has the Platonist made any advance? On the contrary, they have violated the razor that Ockham should have proposed: do not multiply mysteries beyond necessity. Directedness is, to be sure, something of a mystery, one I seek partially to clarify. But why take on this mystery as well as the mystery of Platonism given that the Platonist position does nothing at all to clarify the first mystery but instead relies on it? On my account, directedness is a first-order, intrinsic feature of the concrete world, the irreducible finality without which we can explain very little. On the Platonist account, indeed on any relational account, we still have irreducible directedness, albeit at the second level, and now it becomes a more mysterious, relational affair. And for the Platonist in particular, the second-order mystery of directedness detaches itself from the world of the concrete altogether. We should try to minimise our mysteries.

So how does directedness fit into the broad picture of potentiality as specific indifference? I have said nothing about 'pointing', 'aiming at', and the like. Bird, following Mumford, worries that we should have to attribute intentionality to vectors, or to falling rocks that are 'directed' to the road below. Yet this is a confusion born of the woolliness of the term 'directed'. The direction of a falling rock is purely a spatio-temporal notion; that of a vector may be spatio-temporal, otherwise physical, or purely logical or mathematical. All of these are ways in which powers can be manifested, but the directedness of the power itself is always a matter of specific indifference, a concept that carries no essentially spatio-temporal, physical, or other connotation. Rocks have specific indifference: the power to resist an imposed force is essential to inertial mass. Rocks resist imposed forces, they do not vanish; but the way in which a particular rock resists a particular force depends on the rock, the force, and the circumstances. Similarly, falling to the centre of the Earth is essential to an object, such as a rock, with gravitational mass and within the Earth's gravitational field. But whether it falls in the spatio-temporal direction of a road or a stream is a matter of indifference, not specificity. Its particular direction is not its directedness but a manifestation of its directedness, that is, a manifestation of its specific indifference. Again, it is superfluous to metaphysical requirements that there be any 'aiming', 'striving', 'planning', or any concept of that to which the object with a given power is specifically indifferent. 
This was never the right way to read either Aristotle or for that matter Aquinas, but it remains the distorting Galilean-Cartesian-Spinozistic lens through which the history of ideas was-and continues to be-misread.

Two further points should be made before concluding this section. To recap the general point first: a good way of understanding directedness is in terms of finality; and a good way of understanding finality is in terms of specific indifference. Specific indifference is always a way of understanding the essence of an object. The first additional point, then, is that this is so whether directedness involves the essence more or less generically. Mammals have mass, and as such can shatter windows, but if poor Bessie the cow is launched at a pane of glass the power she manifests involves her essence more generically (no consolation to her) than the power she manifests when feeding her young. The more completely an essence is involved in the manifestation of an object's power, the less generic (more specific) is the involvement of the essence. The second point is that directedness can involve powers that are either essential or contingent. Mellor's example of water is one illustration ${ }^{52}$ : hot water dissolves more compounds more rapidly than cold water, though the temperature of the water is contingent; still, in both cases the specific indifference displayed by its solvent power derives from its essence, which is given in part by its molecular structure. Again, an object that is only contingently red has the contingent power of reflecting light of a certain wavelength; but the directedness of that power derives from the object's power of reflecting whatever wavelength corresponds to the colour it actually has - and this is essential. This second case is one of remote and proximate involvement of essence. The contingent red-involving power derives more remotely from the essence of the coloured object than the necessary light-reflecting power.

Having sought to remove some of the spookiness surrounding 'directedness', I now turn to the equally dark notion of 'inexistence'.

\section{Inexistence: failures of exportation and truth}

When Brentano spoke of 'intentional inexistence' [intentionale Inexistenz], ${ }^{53}$ he meant the 'esse intentionale', the 'intentional existence' or 'intentional being' of the scholastic philosophers. Since one of the oft-cited features of intentionality is that intentional objects need not exist (a child's thoughts about the Tooth Fairy, my wondering about the future prime minister), 'inexistence' has come in many quarters to be equated with 'non-existence', inasmuch as commentators have taken intentional inexistence simply to be that feature of intentionality whereby intentional objects need not have real existence $^{54}$ (what the scholastics sometimes called 'esse reale' or 'esse naturale'). The move is natural but a misunderstanding nevertheless. The 'inexistence' of Brentano and the scholastics pertains more to directedness than to possible non-existence. Possible non-existence is, however, a consequence of inexistence: it is more helpfully

\footnotetext{
52 Mellor (1991, p. 107).

53 Brentano (1995/1874, p. 68).

54 Place $(1996$, pp. 92, 100) is guilty of this conflation.
} 
considered in terms of the failure of quantifier exportation ${ }^{55}$ and/or permissible falsity of a proposition embedded within an intentional context. ${ }^{56}$ Just as my desire for world peace does not entail that there is or ever will be world peace, so my wondering whether it will rain tomorrow does not entail that it will rain tomorrow. Having clarified this, for simple convenience's sake I will now use the term 'inexistence' as a shorthand for failure of exportation and/or permissible falsity.

A little consideration demonstrates that for all the apparent centrality of inexistence to intentionality, it is by no means essential to it and so fails to be a 'mark of the mental'; philosophers have arguably wasted a lot of time discussing it in this context, and may even have seriously distorted the whole debate. For a start, propositions embedded in the modal context 'It is possible that...' are also permissibly false, and if they are existentially quantified then exportation fails. ${ }^{57}$ Even if (itself questionable) 'It is possible that...' creates a context that is intensional with an 's', it is not an intentional context whether mental or physical. The same goes for 'It is probable that...', at least if probability is interpreted objectively (that is, as having nothing to do with belief). Failure of exportation/existential generalisation and permissible falsity can be found where there is no intentionality of any sort, and conversely neither of them apply in certain contexts that are clearly intentional, namely those created by factives. ${ }^{58}$ (1) Exportation/existential generalisation is clearly valid in the case of factives where the complement is a direct object, such as ' $\mathrm{S}$ knows $\mathrm{X}$ ' (knowledge by acquaintance), ' $\mathrm{S}$ sees $x$ ', 'S hears $x$ ', 'S is aware of $x$ ', 'S realises $x$ ' ${ }^{59}$ (2) Permissible falsity fails, and so truth is entailed, in the case of factives with a propositional complement, such as 'S knows that p', 'S realises that p', 'S regrets that p'. I for one see no room for debate about at least some sensory verbs, properly understood in their context; even if we had to disambiguate 'see', for instance, so as to separate factive from non-factive cases, the former would be sufficient to make the point. But even if no sensory verbs were either factive or had a factive interpretation, it is beyond question that 'know' is both factive and creates an intentional context, and only one case is needed. I will leave it as intuitively clear for now that 'know' is intentional, adding merely that intensionality

\footnotetext{
55 As well as the failure of existential generalisation. The basic idea is that from, say, 'Fred is scared of a vampire' we cannot infer 'There is a vampire of which Fred is scared' (we cannot export the existential quantifier from within the context of the verb to a position outside the context of the verb). In addition, we cannot infer from 'Fred loves Zeus' to 'There is someone Fred loves' (failure of existential generalisation). Possible non-existence, then, prevents there being general rules allowing exportation or existential generalisation in the context of intentional verbs.

56 Martin and Pfeifer (1986); Lycan (1969); Chisholm (1957, pp. 170-171).

57 Well, I am assuming that the Barcan formula is false for evidently compelling metaphysical reasons, irrespective of any formal questions about the best system of modal logic. If it is possible that there are golden mountains, it does not follow that there is anything that is possibly a golden mountain-if, say, only a mountain is in the running for possibly being golden, and if no non-golden mountain ever could have been golden or ever could become golden without being replaced by a numerically different mountain. (If you don't like this example, others are easy to conceive.)

58 Or, more narrowly, 'verbs of cognitive achievement', as Place puts it (1996, p. 107).

59 Examples: 'Fred sees Gail' entails 'There is someone Fred sees' (generalisation); 'Fred sees someone beautiful' entails 'There is someone beautiful whom Fred sees' (exportation).
} 
with an 's' has something to do with it ${ }^{60}$ — but this is only the surface of the story, as we shall see.

Not only does inexistence fail as a 'mark of the mental', but it also fails as a 'mark of the dispositional', to use Place's phrase: in other words, there is no general phenomenon of failure of exportation/existential generalisation or permissible falsity in respect of powers. Martin and Pfeifer, endorsed by Place, make much of the fact that many power ascriptions do not entail the truth of the manifestation condition embedded within the relevant context or implied by the ascription, nor the existence of one or more of the objects that are essential to the fulfilment of the condition. (1) 'This vase is fragile' does not entail 'This glass will break' (i.e., that it will break at any time, let alone any particular time, in its actual career). (2) 'This glass is capable of being smashed only by a one kilogram rock' does not entail 'There exists a one kilogram rock'. (3) 'Protons attract electrons' does not entail 'There are electrons'. 61 (4) 'Acid can turn this litmus paper red' does not entail 'This litmus paper will turn red'.

What physical intentionalists overlook, however, is that there are powers whose manifestations are guaranteed. (1) 'All men are mortal' entails 'This man will die'. (2) 'Uranium 238 has a half-life of 4.5 billion years' entails 'On average, fifty per cent of this sample of uranium 238 measured at time $t$ will have decayed at $t+4.5$ billion years.' A few remarks about these examples are in order. ${ }^{62}$ First, (1) might look like a mere logical claim rather than a power ascription, but it is the latter. It is also not a mere description of what happens to befall all humans, nor even of a physically or metaphysically necessary connection between humans and mortality. It is, rather, shorthand for the ascription of a power to humans-obviously not an active power since dying is not an action, but a passive power, namely the potentiality concerning what happens to all humans in virtue of their very essence. ${ }^{63}$ Secondly, it might be argued that (2) is not a power ascription since it ascribes no power to any particular entity: half-lives concern radioactive elements in general, but there is no metaphysical 'trickle down' to any individual isotope. This is not quite right, however, since each isotope, simply in virtue of being an instance of the kind with the relevant half-life, must have some power of decay instantiating the power of the kind; it's just that whether and when this power will be manifested is, so physics tells us, in principle unpredictable. Even if true, though, this will not make my point since I am arguing

\footnotetext{
60 Both Chisholm (1957, p. 171) and Place (1996, p. 107) recognise this, but as we shall see the story goes deeper than mere intensionality.

61 Compare 'Protons are attracting electrons'.

62 One specious objection is easily disposed of, namely that all bearers of a given power can be wiped out before the power manifests, so no power can have a guaranteed manifestation. Reply: (i) if the manifestation is precisely ceasing to exist, as with human mortality, then wiping out the power-bearers is one way of manifesting the power. (ii) For powers with guaranteed manifestations that do not consist simply of ceasing to exist (e.g. radioactive half-lives), 'guaranteed to manifest' means 'guaranteed to manifest as long as the power-bearer exists'.

63 Needless to say, the real distinction between active and passive powers is not an easy one to make out. It might plausibly be argued that if there is any distinction to be had here it is merely conceptual. Although I believe the real distinction can be made out there is no space for a detailed defence.
} 
that in the case of (2) permissible falsity fails; but if the power I am appealing to is the individual power of an arbitrary isotope the argument itself fails, since it is always permissibly false, of any individual isotope of $U 238$, that it will decay at $t+4.5$ billion years. Rather, the correct appeal is to the power of the kind, Uranium 238. This does descend to any given sample, so we could just as well appeal to the power of the sample, insisting that there are powers of kinds, and even powers of samples of kinds, that do not descend to individual instances of the kind in question. In the case of radioactive decay this seems to be what the physics forces us to say, as long as we are not sceptics about powers in the first place. And it will be enough to make the point that permissible falsity fails here. The third point is that the failure of permissible falsity has nothing to do with the existence, if there be such, of so-called 'surefire dispositions', ones whose manifestation is produced deterministically: ${ }^{64}$ the existence of radioactive decay, which involves a guaranteed manifestation that is nonetheless indeterministic, proves the point. ${ }^{65}$ Rather, the failure derives from the essences of certain kinds of thing. The powers they have, however completely or incompletely, and however proximately or remotely, are bound to be manifested. ${ }^{66}$ This is no more an issue of determinism than that all reptiles have hearts or that objects with mass exert gravitational force on each other. ${ }^{67}$ Even when causation is part of what the power's manifestation consists in, as it usually is, the question of whether the causation at hand is deterministic is distinct from whether the manifestation is necessary given the existence of the power.

The upshot of this section is that 'intentional inexistence', interpreted as permissible falsity and/or failure of quantifier exportation or existential generalisation, looks like a bright red herring when it comes to comparing mental intentionality and physical powers. In both cases it sometimes applies and sometimes does not. This no more suggests a metaphysically interesting similarity between the two than the mere occasional sharing of some feature points to a metaphysically interesting similarity between donkeys and diamonds. That said, however, factives and their physical analogues in cases of guaranteed manifestation do after all help us to home in on what really matters when it comes to mental intentionality, and reinforce the picture of finality as underlying both the mental and the physical.

\footnotetext{
64 This is the standard interpretation of Prior et al.'s 'causally operative sufficient condition' for manifestation (1982, p. 251).

65 We should not be misled by the fact that the manifestation, in the case of radioactive half-lives, is probabilistic. The strict definition of half-life is that, on average, half of the isotopes of a given sample will have decayed by the end of the relevant time. It is not just the probabilistic nature of the decay that requires this stipulation, but also the fact that some samples have an odd number of isotopes. The manifestation of the decay power, albeit a phenomenon that occurs on average, is guaranteed. Suppose that a given animal population was guaranteed to have, on average, 2.3 offspring per female: the manifestation would not be deprived of its guarantee just because it was an actuality that obtained on average.

66 A surefire or deterministic disposition, on the other hand — say, of a given object to fall when dropped-is bound to manifest only if the stimulus is present.

67 We should not get exercised here about ceteris paribus conditions and all the ways in which powers can be blocked. A metaphysically satisfying story about these can be told, one that is consistent with the necessity of manifestation of certain powers. For more, see Oderberg (2011).
} 


\section{Intensionality with an ' $s$ '}

We know that both factives and powers with guaranteed manifestations violate 'intentional inexistence' interpreted as failure of exportation/existential generalisation and/or permissible falsity. Still, both display finality understood as specific indifference. Powers with guaranteed manifestations, like all powers, have as part of their essence a specific range of manifestations within which the power is indifferent to the circumstances in which a manifestation within the range occurs. More properly and significantly, we should perform what might be called 'objectual descent' and speak of the power possessors rather than the powers on their own: bearers of powers display specific indifference in virtue of the powers they bear.

As to factives like 'know', they too can be assimilated to other cases of mental intentionality: factivity makes them no less intentional than mental acts and states complying with inexistence such as wanting, hoping, and fearing. The question then is: do all these mental acts and states display specific indifference? As I will discuss in more detail later, mental acts and states are not themselves powers. Humans ${ }^{68}$ have the power of knowing, desiring, hoping for, and fearing things, but these powers (all instances of the rational power) are not the same as their exercise. On the contrary, the exercise of the intentional powers looks like their manifestation, and manifestations are actualities, not potentialities. So the very suggestion that there should be physical intentionality in powers as a straight metaphysical carry-over from mental intentionality understood as the manifestation of intentional powers looks doomed from the start.

Yet for all that this may be a problem, we can still affirm that mental intentionality, whether factive or not, in its actual state - the very exercise of the intentional powersdoes display finality understood as specific indifference, and this is where we begin to find the key to what really distinguishes the mental from the physical (at least where the mental is understood as rational mentality, as it is here). ${ }^{69}$ The way through to an answer goes via intensionality with an 's'. Now both Bird ${ }^{70}$ and Place ${ }^{71}$ argue, contra both Molnar ${ }^{72}$ and Martin and Pfeifer, ${ }^{73}$ that parallels to the intensionality with an 's' that we find in contexts of mental intentionality cannot also be found in physical powers. We are familiar with such truisms as that from

\section{(1) Andrew believes that George Eliot wrote Middlemarch}

\footnotetext{
68 The only rational agents I am considering for now, though I will broaden the analysis later.

69 Note that in speaking of a mental act or actuality's displaying finality I am not suggesting the act has its own finality distinct in kind from the underlying mental power manifested by the act. There is one kind of finality (captured, as we will see, by the phenomenon of abstraction) but in the case of a mental act finality is displayed by the exercise of a mental power that possesses finality. To put it the other way, the hallmark of mental powers is their specific kind of finality, the kind of finality that is manifested or displayed when the mental power is exercised. Similarly, the finality displayed by the actual breakage of a glass when struck is possessed by the glass's fragility, which is a power, and hence by the glass itself, which bears the power.

70 Bird (2007, pp. 121-123).

71 Place (1996, pp. 108-112).

72 Molnar (2003, pp. 64-46).

73 Martin and Pfeifer (1986, pp. 532-533).
} 


\section{(2) George Eliot is Mary Ann Evans}

it does not follow that

\section{(3) Andrew believes that Mary Ann Evans wrote Middlemarch}

unless he also believes that Mary Ann Evans is George Eliot. It would be nigh incredible that anything similar could be found in the case of powers. Molnar's example is: ${ }^{74}$

(4) Acid has the power to turn this piece of litmus paper red

(5) Red is the colour of post boxes

(6) Acid has the power to turn this piece of litmus paper the colour of post boxes.

Molnar claims that (6) does not follow from (4) and (5). It is evident, though, that if 'the colour of post boxes' is interpreted rigidly as 'the actual colour of post boxes' then acid certainly has the power to turn litmus paper that colour. We only hear (6) as not following from (4) and (5) if 'the colour of post boxes' is interpreted as 'the colour of post boxes, whatever that colour happens to be'. As Bird succinctly puts it, ${ }^{75}$ acid has no power that tracks the colour of post boxes. So the parallel with the belief example fails: intensionality with an 's' still applies in the latter case despite the rigidity of the relevant referring terms.

Of more interest, perhaps, is Martin and Pfeifer's attempt to prove physical intensionality with an 's':

(7) Acid A was able to turn litmus paper $\mathrm{P}$ into the only pink object $\mathrm{O}$ at location $\mathrm{L}$

(8) The only pink object $\mathrm{O}$ at location $\mathrm{L}$ is the only object $\mathrm{M}$ of mass $f$ at $\mathrm{L}$

do not entail

(9) Acid A was able to turn litmus paper $\mathrm{P}$ into the only object M of mass $f$ at location L.

Place has a rather convoluted response to this gnarly example, arguing in the alternative as follows. ${ }^{76}$ (i) Even if this example demonstrates physical intensionality with an 's', all the terms in the complement are singular, whereas intensionality with an 's' in mental contexts applies also to general terms but this has no physical analogue. (ii) Even if intensionality with an ' $s$ ' only applies to co-referring singular terms this example does not demonstrate physical intensionality with an 's' because the putative power of acid A is no power at all, due to its being wholly limited to a particular object, and a particular event, at a particular place, whereas genuine powers are 'open-ended'.

Place's objections are easy to dispose of. Taking (ii) first, it is easy to insert a range of manifestation conditions along some dimension, thus endowing the alleged power of acid A with some 'open-endedness' and thus qualifying it as genuine, for instance:

( $7^{*}$ ) Acid $\mathrm{A}$ was able to turn litmus paper $\mathrm{P}$ into the only pink object $\mathrm{O}$ at location

$\mathrm{L}$ at any time $\mathrm{t}_{\mathrm{i}}$ between times $\mathrm{t}_{1} \ldots \mathrm{t}_{\mathrm{n}}$

\footnotetext{
74 With numbering changed from the original.

75 Bird (2007, p. 122).

76 Place (1996, pp. 108-112).
} 
$\left(8^{*}\right)$ The only pink object $\mathrm{O}$ at location $\mathrm{L}$ at any time $\mathrm{t}_{\mathrm{i}}$ between times $\mathrm{t}_{1} \ldots \mathrm{t}_{\mathrm{n}}$ is the only object $\mathrm{M}$ of mass $f$ at $\mathrm{L}$ at any time $\mathrm{t}_{\mathrm{i}}$ between times $\mathrm{t}_{1} \ldots \mathrm{t}_{\mathrm{n}}$

which still do not entail

(9*) Acid A was able to turn litmus paper $\mathrm{P}$ into the only object $\mathrm{M}$ of mass $f$ at location $\mathrm{L}$ at any time $\mathrm{t}_{\mathrm{i}}$ between times $\mathrm{t}_{1} \ldots \mathrm{t}_{\mathrm{n}}$.

In other words, it does not appear essential to Martin and Pfeifer's example that it be wholly particularised in the way they make it. Returning now to Place's objection (i), consider that:

(10) Poison $P$ was able to turn red squirrels into sick red squirrels

(11) Sick red squirrels are native British squirrels

do not entail

(12) Poison P was able to turn red squirrels into native British squirrels.

Here only general terms are used in the complement of the power context, yet although they co-refer, substitution fails to preserve truth. Further, 'sick red squirrels' is being used rigidly, as in 'the actual sick red squirrels', namely the ones that, in the imagined case, are the familiar British ones. Similarly, 'native British squirrels' is being used rigidly to refer to the familiar British ones, not to native British squirrels whatever kind that may happen to be in an arbitrary possible world (such as one in which the grey squirrels are native). Moreover, Place's objection has nothing to do with general terms referring to essential kinds rather than accidental kinds: any general term will do, and 'sick red squirrel' is a perfectly kosher general term. In any case, we can stipulate further so that the general terms all refer to essential kinds (rather, the one essential kind): suppose P turned every red squirrel sick without exception; suppose the sickness to be a minor genetic mutation expressed as a relatively insignificant but permanent functional disability; and suppose the mutation to be part of the heritable genome; then we can be sure (11) is true, in other words that there is genuine co-reference to one and only one kind, and an essential kind at that. Yet we still rightly deny that $\mathrm{P}$ turned sick squirrels into native British squirrels.

Does this mean Martin and Pfeifer are vindicated - that not only have they provided a legitimate example of physical intensionality with an 's' involving singular terms, but that a parallel one can be constructed using general terms, contra Place? Not at all, because the failure of the inference to go through in both (7)-(9) and (10)-(12) has nothing to do with intensionality with an 's' and everything to do with John Buridan's 'raw meat' sophism ${ }^{77}$ :

(13) Yesterday you bought raw meat

(14) What you bought is what you ate

(15) You ate raw meat.

77 This is the second sophism of Chap. 4 of his Summulae de Dialectica: Buridan (2001, p. 877). 
Now (15) evidently does not follow from (13) and (14); the question is why. There is, perhaps surprisingly, a fair bit of debate about precisely what the fallacy is, with general agreement that it is either, or closely related to, the fallacy of secundum quid, which is itself the same as, or closely related to, the fallacy of accident. ${ }^{78}$ For our purposes, it is enough to observe that the raw meat fallacy derives from a failure to take into account the fact that the meat was cooked before it was eaten: you ate meat, to be sure, but one of its characteristics had changed between the time you bought it and the time you ate it. This is sufficient to enable diagnosis of why both Martin and Pfeifer's putative case of physical intensionality with an 's' (7-9, the acid and the litmus paper) and my parallel case using general terms (10-12, the red squirrels) are fallacious. In the acid example, the fallacy derives from a failure to take into account the fact that the litmus paper was the only object M of mass $f$ at L before the acid acted on it. In the squirrel example, the fallacy derives from the failure to take into account the fact that the red squirrels were native British squirrels before the poison acted on them. In the raw meat sophism, there is a failure to take into account something that has changed; in the acid and squirrel fallacies, the failure is to take into account something that has stayed the same. Here we have a unified diagnosis (albeit informal) of all three fallacies, with no need to invoke, and no obvious role for, putative physical intensionality with an ' $s$ ' in the latter two. (And we certainly should not think that Buridan's sophism proves 'ate' to be intensional!)

We have, I submit, enough material to show that physical intensionality with an 's' is illusory. This leads naturally to the thought—which, as we shall see, I denythat intensionality with an ' $s$ ' is, in the end, what distinguishes the mental from the physical. As we saw, both factives and guaranteed manifestations of physical powers demonstrate that their correlative contexts violate exportation/generalisation and/or permissible falsity. Both, however, display finality as specific indifference as much as do non-factives and powers with non-guaranteed manifestations. Uranium 238's half-life is indifferent to whether any individual isotope decays at all and hence to which $50 \%$ of a given sample will decay according to the half-life, as well as to the spatial location of any sample manifesting the half-life. Human mortality is indifferent to which humans there are, when, where and how they die. The specific indifference of such powers seems to be on all fours with that of all the rest.

When it comes to factives such as knowing, seeing, regretting, and the like, the finality displayed is like that of non-factives such as believing, wanting, and hoping. But in what way do any of these mental states or acts display finality understood as specific indifference? The general answer is that they all, without exception, involve thinking about the object of the state or act in some ways rather than others. The special answer in each case is that for any particular mental act or state $\mathrm{M}$ and object $\mathrm{O}$ involving finality, the subject of that act or state $\mathrm{Ms}$ about $\mathrm{O}$ in some ways rather than others. This is not merely a matter of the 'descriptive character of much thought and in particular the fact that descriptions may be incomplete', ${ }^{79}$ but of the incompleteness of thought generally, at least for finite rational beings such as ourselves. And it is not

\footnotetext{
78 For an interesting discussion, see Walton (1990).

79 Bird (2007, p. 125).
} 
just that thought is incomplete, but that it must be incomplete if there is to be any thought at all-just as finality in the physical world is a precondition for any efficient causation whatsoever.

If I know that George Eliot wrote Middlemarch but not that Mary Ann Evans did so, then there is a certain descriptive incompleteness in my thought about either the person George Eliot/Mary Ann Evans, or the novel, or both. A child might wonder whether $2+2=4$ without wondering whether the sum of 2 and 2 is the second even number, again due to descriptive incompleteness in thought, which is better categorised as incompleteness of information. But a person might also know something directly ('by acquaintance'), say a particular shade of red, without knowing it in all possible lighting conditions and all possible colour contexts. Here, we stipulate that there is no descriptive lack, and hence no information gap if we restrict information to what can be described. But if knowing something directly counts as information without description, then knowing the shade of red but not under all possible conditions also counts as a lack of information.

The same line of thinking cuts us further adrift from intensionality with an 's' pure and simple (understood in terms of referential opacity and failure of substitutability), and even from lack of information, when we consider highly general thoughts such as the thought that something might happen, that someone is in the room, or that everything that happens has a purpose. Trying to find intensional contexts here involves Procrustean manoeuvres that serve little purpose in advancing our understanding. The same, I would argue, goes for simple, non-descriptive singular thoughts such as Jane's thinking about John—not thinking anything in particular, just pondering him or having him before her mind's eye, as it were. True, if John is the local bank robber it does not follow that Jane is thinking about the local bank robber unless she knows the identity, but what is gained by the observation? One can ponder things, turn them around in one's mind, gaze at them either internally or with a physical eye - all acts of intentionality. Whether we go on to characterise all such acts and states as intensional with an 's', inasmuch as one can produce canonical forms for them in which an intentional verb takes a complement within which referential opacity, or some failure of substitution salva veritate, can be demonstrated, depends on how far we are willing to distort both mind and language for the cause. Given that the cause is understanding intentionality, and hence at least part of the essence of mind, I doubt that such contortions will give us what we need.

Intensionality with an 's' clearly features in most typical cases of mental intentionality, factives included. And it would be wrong to dismiss its relevance for understanding the mental as opposed to the physical, as Searle does. ${ }^{80}$ Place is right to insist that intensionality with an ' $s$ ' is not the essence distinguishing the mental from the physical, but again overly dismissive in suggesting that it 'arises only in the case of a quotation of what someone has said or would be expected to say, where to make such a substitution is liable to misrepresent what has been or would be said.' ${ }^{81}$ Even if Place is right about the essential link between intensionality with an 's' and quotation

\footnotetext{
80 Searle (1983, p. 24).

81 Place (1996, p. 119).
} 
(a question we need not resolve here), to think that there is no essential link between quotation and the mental is bizarre. We cannot begin to understand why quotational contexts are intensional with an 's' without a grasp of the way in which what a person says or might say represents or expresses what they believe, wonder about, suppose, desire, and the like.

The problem with intensionality with an 's', then, is not that it has nothing to do with intentionality, that it is a diversion or that emphasising it hampers our attempt to grasp the essence of the mental, but that by concentrating on it we merely scratch about on the surface of something far deeper. To this extent, I would argue that Elizabeth Anscombe was closer to the truth when she posited the 'possible indeterminacy of the [intentional] object' as one of the 'connected features' of 'intentional objects' ${ }^{82}$ The other two features are 'possible non-existence' (inexistence) and 'non-substitutability' (intensionality with an 's', referential opacity), but what is interesting is that she is clear enough that these two features derive from, are made possible by, the first. That is, what Anscombe calls 'indeterminacy' is for her of primary importance in understanding intentionality. And although the terms 'abstract' and 'abstraction' appear nowhere in her analysis, I claim that these are precisely what she means by indeterminacy. ${ }^{83}$ The position we have arrived at, then, is that both physical powers and mental intentionality display finality, understood as specific indifference. It is no surprise, then, that many of the features to which theorists of intentionality have traditionally been drawn are found in both cases - the very fact exploited by some power theorists in defence of the thesis of 'physical intentionality'. Intensionality with an 's', however, despite some ingenious attempts, fails to carry over to the physical. This is because intensionality most clearly and intimately reflects, or is a classic symptom of, the fundamental mental process of abstraction, for which there is no correlate among the physical powers. Yet intensionality with an 's' is not always found where there is abstraction at work, unless we stretch the former term to the point of its losing any distinctive interest. We must now turn to abstraction itself, as essential to intentionality, in order to see conclusively how mental and physical finality differ.

\section{Abstraction}

It was always problematic to think of powers as having intentionality because the mental states to which the same intentionality is attributed are not themselves powers, even though they presuppose and depend on a range of mental powers. This is not to deny that some mental states are best thought of as dispositional rather than occurrent (in the classical terminology, potentialities rather than actualities). Perhaps every kind of mental state has both dispositional and occurrent instances; knowledge might be one example. Yet it will not do for the physical intentionalist to retrench by limiting their thesis to dispositional mental states only, so as to preserve the analogy with

\footnotetext{
82 Anscombe (2002/1965, p. 58).

83 Note that Martin and Pfeifer, as well as Molnar, place great weight on indeterminacy in their accounts of physical intentionality, but what they mean is significantly different from what I claim Anscombe had in mind. I criticise their accounts in the next section.
} 
the purely physical. After all, the claim under consideration is that intentionality is not the hallmark of the mental but is common to the physical; to restrict the mental states under consideration to the dispositional only seems arbitrary and lacking in independent motivation. Physical intentionalists muddy the waters by a liberal use of dispositional language in the analysis of intentionality, perhaps because it makes their case intuitively more appealing: if mental intentionality is itself a feature of mental dispositions, why should we be surprised to find physical intentionality in physical dispositions? Place goes as far as to claim that '[a]ll mental states, it turns out, are dispositional in nature. ${ }^{84}$ It is not Place's lack of argument for this sweeping claim that is the problem, but that it is patently false. Fred's thought about birds- the thought he has right here, right now, as he watches them through his binoculars-is manifestly not dispositional inasmuch as it is not a power. It is an actuality, something in which Fred is actually engaged. It might be dispositional in the sense that Fred could not have the thought without being disposed to respond in various ways to linguistic or environmental stimuli. Actual mental states all entail the existence of correlative powers, if the general thesis I argued for earlier is correct. At its most basic, no one thinks without having the power to think. But the actual thought is not the power, it is a manifestation of the power, an exercise of it; and this manifestation is an actuality. ${ }^{85}$

So we should never have expected intentionality as the mark of an actuality-of actual thoughts - to be also the mark of a potentiality, that is, of (physical) powers. Actuality and potentiality are fundamentally different kinds of being. To forget this risks being misled into conceiving of unmanifested powers as somehow 'thinking' about their possible manifestations, just the worry that produces atavistic fears of animism or panpsychism in the opponents of physical intentionality. Either the physical intentionalist is forced to treat actual mental states as potentialities, which they are not; or he is compelled to regard physical potentialities as actualities-states of actual, thought-like behaviour by powers-which, again, they are not.

The debate over physical intentionality, then, has caused metaphysicians to look in the wrong place when comparing and contrasting the mental and the physical. Instead, we should be focusing on the phenomenon of abstraction. There is a lot of confusion

\footnotetext{
84 Place (1996, p. 116).

85 Once again, note my assumption of a real distinction between powers and actualities. The pandispositionalist is unlikely to be impressed given that she will consider a thought to be just another power, not a genuine actuality. Still, one can accept that in virtue of Fred's thought about birds he has various dispositions, including the disposition to have further thoughts. That is not only compatible with my position but an integral part of it. But the pan-dispositionalist idea that, strictly, the thought $i s$ a disposition is, as I have argued earlier, a mistake. Moreover, the pan-dispositionalist cannot escape so easily the force of my insistence on a disanalogy between the mental and the physical. For the whole appeal of the analogy drawn by physical intentionalists in the first place rests on the idea that physical powers interestingly resemble mental states in respect of directedness. This presupposes that mental states are sufficiently different from physical powers to make for an interesting and enlightening analogy. If, on the other hand, mental states are just more powers, where is the analogy at all? What is so special about the mental? It is hard to see, on pan-dispositionalism, how the intentionality of thought could cast any light on the directedness of powers if thoughts are themselves just more powers whose directedness is sought to be explained in the first place. In effect, this raises a dilemma for the physical intentionalist: either mental states and physical powers are too dissimilar to be assimilated at any level deeper than their common finality (my position); or they are too similar for one to cast any light on the other (as pan-dispositionalism seems to imply). Either way, there is no genuine analogy.
} 
and unintended obfuscation when it comes to considering abstraction and its role, if any, in the debate over 'physical intentionality'. For a start, there is the potential for misunderstanding in the terminology itself. Abstraction in a thought does not entail that the thought is about anything abstract in the sense of 'abstract object'. Indeterminacy in thought (a term used both by supporters of physical intentionality, such as Molnar and Martin \& Pfeifer, and by opponents such as Bird) neither implies that a thought is vague in the sense of having an unclear content, nor that it has a content involving 'borderline' cases, nor that if a thought is about something with 'borderline' cases the vagueness of the thought is anything additional to the vagueness of what the thought is about.

There is also a muddle in what philosophers have said about the role of abstraction both in intentionality per se and in the debate over physical intentionality-Anscombe herself being no exception. She famously observes: 'the descriptions under which you intend what you do can be vague, indeterminate. (You mean to put the book down on the table all right, and you do so, but you do not mean to put it down anywhere in particular on the table - though you do put it down somewhere in particular.) ${ }^{86}$ Using 'vague' and 'indeterminate' interchangeably does not help the cause of understanding: there is nothing vague about intending to put a book down on a table, unless one wishes to soritify ${ }^{87}$ the boundaries of the table, which is evidently not what Anscombe means. Nor is the content in any way unclear. When you mean to put a book down on a table the only indeterminacy is in the abstraction involved in the thought: no particular location on the table is within the scope of your intent; anywhere will do. Consider how hard it would be to form the intention, let alone communicate or execute it, if you tried (per impossibile) to eliminate all abstraction: 'I mean to put the book here on the table, and by "here" I mean...' with no prescinding at all from particular spatial co-ordinates of any kind. Whereas the original intention is perfectly non-vague, trying to eliminate abstraction positively introduces vagueness where there was none before. You simply must abstract, thinking of your book and/or table in some ways rather than others.

Molnar too, ${ }^{88}$ as Bird notes, ${ }^{89}$ sees indeterminacy in physical powers as paralleling two kinds of indeterminacy in mental intentionality- 'borderline' cases and incompleteness of descriptive content. The first, as I noted, is in no way essential to intentionality (except insofar as 'borderline' cases can be conjured up in everything under and including the sun) and in no way the same as abstraction. But Molnar confuses matters further by alleging an analogy between indeterminacy as descriptive incompleteness in thought and indeterminism as found in powers with essentially probabilistic manifestations such as radioactive decay. There is nothing incomplete in the half-life of U 238 even though no event or object, so physics tells us, causally necessitates the decay of any particular isotope at any particular time. In any case, as I have also argued, the finality displayed by intentionality does not require descriptive incompleteness.

\footnotetext{
86 Anscombe (2002/1965, p. 56).

87 I apologise for not being able to think of a better term for 'apply a sorites argument to' .

88 Molnar (2003, p. 64).

89 Bird (2007, pp. 124-125).
} 
Things get more interesting, however - and we get closer to the heart of the matterwhen considering the sort of idea Martin and Pfeifer have in mind when they appeal to Anscombe's other famous observation ${ }^{90}$ : 'I can think of a man without thinking of a man of any particular height; I cannot hit a man without hitting a man of some particular height, because there is no such thing as a man of no particular height. And the possibility of this indeterminacy makes it possible that when I am thinking of a particular man, not every true description of him is one under which I am thinking of him.' Martin and Pfeifer note ${ }^{91}$ that what Anscombe must mean is that 'when I am thinking of a man who has a particular height, I need not be thinking of him in terms of his particular height.' True enough, but it cannot be all she means: for I can also think of a man without thinking of a man of any particular height if I am not thinking of a 'particular, existing, man' 92 but rather thinking of some man or other, as in 'Think of a man, and what he would do if...' or 'Think of a man; now think of him with a red beard'. (Maybe the latter request is part of a children's game.) Both kinds of thought involve abstraction-that necessary incompleteness of thought involving thinking of something in some ways rather than others, which includes but is not exhausted by prescinding from certain possible components of content that would add further information to the thought.

Now the reason I mention both interpretations of Anscombe's remark-mutually consistent and complementary — is that this actually helps Martin and Pfeifer's case, even though their case ultimately fails. For they want to tie the 'no particular height' thought to the case of solubility in a particular liquid. That salt is soluble in a particular, existing sample of water is not dependent on that sample's being at any particular place, even though it cannot be soluble in the particular sample without that sample's being at a particular place. This is supposed to be analogous to thinking of a particular, existing man-who obviously must have a particular height—but without thinking of him 'in terms' of his particular height. Both cases, I claim, are examples of specific indifference-restriction to an object or range of objects but indifference to particularities of that object or range. Putting the analogy in terms of 'indeterminacy', however, is bound only to confuse. One might suppose, contra both Molnar and Martin $\&$ Pfeifer, that since every manifestation of a power is fully determinate (at least with the deterministic powers), it is 'illusory' to suppose any indeterminacy in what powers 'point to'. After all, 'an infinity of fully determinate objects is not the same as a single indeterminate one.' 93

This objection is equal parts confusion and accuracy. The confusion is between the 'what-forness' of a power, to use Martin's apposite term, and the ways in which the what-forness is realized. No power, and no object of a power, is 'the same as' its concrete manifestations, at least for the physical intentionalist. The physical intentionalist can consistently hold both that every manifestation of a given power is fully deter-

\footnotetext{
90 Anscombe (2002/1965, p. 58).

91 Martin and Pfeifer (1986, p. 534).

92 Martin and Pfeifer (1986, p. 533).

93 Bird (2007, p. 124) contra Molnar. Yet Bird falls into the very trap of which he accuses Molnar, since Bird conflates determinism and determinacy whilst only a few lines later castigating Molnar for conflating indeterminism and indeterminacy!
} 
minate and that what the power is for is not: there is indifference in the power, even if there be no indifference in what actually happens when the power is manifested. To deny the distinction is to beg the question against the physical intentionalist or to misread what he is claiming.

The accurate part of the objection goes along the following lines ${ }^{94}$ : 'If you, Martin and Pfeifer, say that salt has the power to dissolve in this "particular, existing" sample of water W, then the "what-forness" of the power you are attributing to salt is precisely "to dissolve in W". But if W is a particular, existing sample, why are you stopping there? Why are you not expanding the "what-forness" to include also the various "particular, existing" times, places, and circumstances in which salt has the power to dissolve in W? Once you do all of the necessary expansion, it becomes clear that what you are attributing to salt is the power to dissolve in a potentially infinite range of particular samples of water, at a potentially infinite range of times and places, and in a potentially infinite range of circumstances. Each combination of particular sample, time, place, and circumstance will be fully determinate, even if we do not know everything that does happen when salt dissolves in a particular case. In the end, what you should be attributing to salt is the power to dissolve in a potentially infinite disjunction of particular, fully determinate situations, with suitable dots added to cover future or merely possible situations. But a disjunction of determinate manifestations can never add up to an indeterminate manifestation.'

Something has gone wrong. The problem is that Martin and Pfeifer should never have mentioned any particular sample of anything when attributing solubility to a substance. They should have thought more about the second interpretation I offered earlier of Anscombe's 'no particular height' thought. The solubility of salt in water is like the thought of a man in general, not like the thought of a 'particular, existing' man even if the latter is not thought of in terms of his particular height. The power of salt in question is that of solubility in water tout court, just as the laws of nature with respect to solubility do not mention particular samples or circumstances (fully particularised circumstances, that is; they can and do mention kinds of circumstances). Once the power is correctly attributed, the relevant indeterminacy becomes clear, with no threat of arbitrariness: the power is indeterminate in the sense of being determinable by specifying the particular modes of the power, themselves not distinct powers. Salt has the determinable power to dissolve in water, but particular samples of salt have determinate powers to dissolve in particular samples at particular times and places. This indeterminacy in the sense of determinability is, once again, just another way of identifying the specific indifference of salt with respect to solubility in water. All of the determinate manifestations that particular samples of salt display when dissolving in particular samples of water are but manifestations of a single power. The single power is not 'for' any of them in particular, nor identical to a disjunction of any or all of them; rather, the various combinations of determinate powers and manifestations are no more than forms, or better modes, the determinable - and in this sense indeterminatepower can have. The power of salt to dissolve in water is to Fred's thought of a man

\footnotetext{
94 Not something that Bird elaborates; nor does he even mention Martin and Pfeifer in this context.
} 
pure and simple, as the power of a particular sample of salt to dissolve in a particular sample of water (and so on) is to Fred's thought of Napoleon at Waterloo.

Yet for all that we may shore up the physical intentionalist case, it ultimately fails - if the case is that the indeterminacy found in thought is on all fours with the indeterminacy found in powers (the 'only' difference being that thought essentially belongs to conscious beings and physical powers do not essentially do so). For the crux of the difference is the freedom at the heart of abstraction, this being a difference of kind from physical powers, not merely of degree. I have contended that both powers and mental intentionality display specific indifference, but there is a difference in the indifference. For a physical power like solubility, the only freedom of manifestation within the specific range is whatever is allowed by the essence of the power bearer and the essence of the object of the power. ${ }^{95}$ If the power bearer is salt, then however the power is free to manifest is determined by the essence of salt. If water is the object, then however salt's power is free to manifest is determined by the essences of salt and water. For example, salt is free to dissolve in this or that sample of water, at this or that time or place; but it has no freedom to dissolve other than by the breaking of the salt crystals' ionic bonds by the water molecules. It has no freedom to dissolve in the way that sugar dissolves in water, which involves the separation by the water molecules of the sucrose molecules. ${ }^{96}$

To put the point more concretely: although an elementary chemistry textbook might tell you no more about what salt can do in water than that it has the power to dissolve in it, this would be an incomplete description-strictly incomplete in the sense that the whole truth of the matter requires further information about the precise chemical process involved and how it differs from other, superficially similar but deeply different, processes of dissolution. Compare this to, say, a thought Fred has about birds: he considers their various flight characteristics but prescinds from their reproductive characteristics. He is not thinking of birds as animals that fly but do not reproduce: he is thinking of birds as animals that fly without thinking of them as animals that reproduce. ${ }^{97}$ In one sense, Fred's thought about birds is incomplete: he is not thinking everything about birds in one and the same thought; nor could he; nor could any thought be complete in this sense. This is the kind of incompleteness at which we might gesture by calling the thought 'indeterminate'. Nevertheless, Fred's thought is not strictly incomplete in the sense given immediately before: the whole truth of the matter about his bird-thought $i s$ given in the description of it as a thought about the flight characteristics of birds, and this even though he is certainly not thinking of every flight characteristic of birds. The contrast between the thought on one hand and the physical power on the other is clear and precise: the freedom in abstraction means that there are many-infinitely many-ways in which the very same kind of thought (defined by its object) can be had. Fred's thought about birds is the same kind of thought whether it is about their flight characteristics, their reproductive character-

\footnotetext{
95 Leave aside the essence of the circumstances, including the essence of the stimulus, purely for the sake of simplicity.

96 Sodium chloride is not a molecule but an ionic compound: there is a fundamental chemical difference between the process of dissolution of crystals of ionic compounds and of chains of molecules.

97 An important distinction of which Anscombe (1981/1974) reminded us in connection with Hume.
} 
istics, or both, or neither. In the case of a physical power, such as salt's solubility in water, the object of the power-what it is a power for-is as it were 'locked down' by the essence of the power bearer. There is no freedom in the specification of the object: salt dissolves in water in one particular way. The only freedom allowed by the power bearer is circumstantial-in respect of when, where, which samples of water and salt, and in which allowable environmental conditions the power is manifested on a particular occasion. Fred's bird thought also has circumstantial freedom-when, where, why it is had, and so on. But there is a further kind of freedom that is not circumstantial, one that goes to the very content of the thought: that content can be preserved, thus making it the same kind of thought, through variation of more specific elements of the content. This freedom in abstraction means the essence of the thinker does not lock down the content of the thought. ${ }^{98}$

Note that the freedom in abstraction I propose to be at the heart of the disanalogy between mental and physical powers does not rely on a highly specific, and possibly contentious, view about the individuation of thoughts or about identifying the subject matter of a thought. Fred's thought remains about birds whether he thinks of their flight characteristics or their reproductive behaviour, on the assumption that he is thinking about birds at all. If we claim that the flight thought and the reproduction thought are not instances of the same kind of thought because one is about flight and one is about reproduction, then clearly we cannot say that Fred was thinking about birds in the first place. We can always say that Fred was thinking about the characteristics of birds rather than about birds, so we could then legitimately call the flight thought and the reproduction thought instances of the same kind of thought. But we do not have to say this either. Thinkers have all kinds of thoughts in all kinds of succession, with no apparent connections between them, and we are not obliged to say that each thought is some kind of content-preserving variation on a prior thought. My point is simply that it is of the essence of thought that it can work this way, and that it must work this way in general for any being that genuinely has the power of thought.

One might object that in order for this disanalogy between mental and physical powers to go through, I have to rule out the very possibility of multi-track dispositions. ${ }^{99}$ For if there are powers that have multiple kinds of manifestation, doesn't this look more like the case of mental intentionality than the single-track case where only one kind of manifestation is in focus, such as the particular process whereby salt dissolves in water? Moreover, the mere contingent absence of multi-track dispositions (if this be so) is not enough to support my case: I have to show them to be in some

\footnotetext{
98 Apart, of course, from the plausible notion that the essence of the thinker as rational locks down all thought content to what is meaningful, logically possible, and perhaps more. I note here that a materialist, of course, will insist that the content of a thought is locked down by the structure and behaviour of the brain: abstraction vanishes at the neuronal level, and all we find-so the objection goes-are physico-chemical processes that are fundamentally no different, for the purpose of present discussion, from what salt does when it dissolves in water. Needless to say, I have no space here to take on the materialist. All I can do is register the objection and reply that a brute materialist response puts the cart before the horse. It's not that materialism is so evidently true that what I say about abstraction is easily refuted, but that abstraction is so evidently a feature of mentality (in rational thinkers) that the burden is on the materialist to show how it can be captured within their framework.

99 Thanks to an anonymous referee for prompting me to address this.
} 
way incoherent or metaphysically impossible. In reply, I noted previously that the thesis of specific indifference-that specific indifference is the best way to understand powers-is not the thesis that powers/dispositions must be multi-track, but I would now add that whether there are multi-track powers at all is irrelevant to the disanalogy I draw between mental and physical powers. My claim is not that a given mental power has different kinds of manifestation whereas no given physical power has different kinds of manifestation. Rather, it is that the given manifestation of a mental power always, and essentially, may vary both circumstantially and as to specific content, the latter due to the essentially abstractive nature of thought. By contrast, no given manifestation of a physical power may vary in anything other than a circumstantial way, there being no analogue of abstraction in the purely physical. So, to return to Fred, I take his having a bird-thought - a thought about birds - to be a manifestation of his mental power of thought. Given the essentially abstractive nature of thought, that thought could be had in various ways that are not merely circumstantial (variations of time and place, for instance): Fred's thought about avian mating habits is as much a bird-thought as his thought about their nest-building behaviour. By contrast, salt's dissolution in water, which is the manifestation of salt's solubility in water, can only vary circumstantially, not across different kinds of process. Now suppose the existence of a multi-track power: let's take solubility to be such a power possessed by salt. If, say, and with no pretence to scientific accuracy, we take its manifestations to be dissolution in water, dissolution in alcohol, and dissolution in dimethyl sulphoxide, we still see that each manifestation of the multi-track power will consist of a single process that can vary only circumstantially. If there is no analogue of abstraction in a single manifestation, there will be no such analogue in a disjunction of manifestations.

To clarify further, it is important to see that the thesis that thoughts are essentially abstractive is not the same as the thesis that thoughts are essentially generic. The latter is false while the former is true, even though genericity of thought is one way in which thought can be abstractive. So, if Fred thinks about birds in general but no specific kinds of birds, he thinks a generic thought, and this is one way in which his thought is abstract: it abstracts from specific kinds of birds. But his thought must be abstract in other ways as well: if his thought is that birds fly, it abstracts from all the other things birds do; if it is that birds are fun to watch, it abstracts from all the other ways one might interact with birds; and so on. Even the highly specific identity thought that Marilyn Monroe is Norma Jeane Mortenson is abstract but not generic: it abstracts from all the other facts about Marilyn Monroe (at the very least, all the other facts about her name/s). Thoughts, by their nature, must select features of reality as their content; rather, their thinkers must select features of reality as the content of their thoughts, in abstraction from others.

Not so with powers, appearances to the contrary. One way in which a power might be multi-track is due to its genericity: the solubility of salt, for instance, might be manifested by more specific kinds of dissolution, say in liquids of kind $K$, liquids of kind $L$, and liquids of kind $M$. Suppose $K, L$, and $M$, to be themselves genera of liquids, each with more than one specific sub-kind as an instance. Then all we have is a multi-track generic power with several generic manifestations. But we know, of course, that this cannot be the end of the story, since neither salt nor any other substance merely dissolves tout court, nor does salt, on this scenario, merely dissolve in liquids of kinds 
$K, L$, and $M$. The whole story must include the most specific kinds of liquid in which water dissolves - say, in our toy example, water, alcohol, and dimethyl sulphoxide. These will be, as scholastics call them, the infima species, or lowest species, of liquids in which salt dissolves. And for each one of these lowest species of liquid, there will be no indifference as to kind of manifestation, only indifference as to circumstance of manifestation. There is only one kind of process whereby salt dissolves in water, and one whereby it dissolves in alcohol, and one whereby it dissolves in DMSO. If this is not the case, it can only be because of further genera we have not yet identified, that is, kinds of water, alcohol, or DMSO.

This picture of physical powers is no parallel to the abstractive nature of thought. The story of the manifestation of the power of thought—say, of Fred's power to think about birds - ends with whatever bird-thought Fred has: but that thought will always be one of many that Fred could have had, any of which would have manifested the power of thinking about birds, and each one of which would have had a different content. Each of these thoughts will itself be essentially abstract, no matter how specific the thought, and so the correlative power of thinking that thought will have further, multiple manifestation kinds (themselves all abstract as well, ad infinitum). There is only the appearance of a parallel with physical powers. Nothing soluble, salt or anything else, has the unqualified power to dissolve; nothing just dissolves. The whole story of salt's solubility must go beyond its generic powers to the infima species of liquids in which it dissolves. But once we are at the level of infima species, there is no more indifference to kind of manifestation: for each infima species of liquid, there is one and only one way in which salt dissolves in it. By contrast, even the most specific thought a thinking being can have about something, say a singular identity thought, is always no more than one way in which a thinker can have a thought about one (or more) of the objects in that thought. Moreover, that thought itself_-say, that Norma Jeane Mortenson is Marilyn Monroe-is not only the manifestation of a power but is associated with a further, correlative power of the thinker, namely the power to think about NJM's identity with MM: if you can think that $\mathrm{NJM}=\mathrm{MM}$, then eo ipso you can think about NJM's identity with MM, for example that the identity is surprising, or of special historical interest, or a little-known fact. All of these thoughts are manifestations of the power of thinking about the identity. Again, all of them are abstractive in content: some features of the identity are considered, others not. Nothing like this can be found in the world of physical powers, multi-track or not.

Let us take stock. Of course physical powers do not think about their possible manifestations; neither do they 'think' about them. For all its suggestiveness and for all the truth underlying the idea of physical intentionality, there is no advance in metaphysical understanding to be gained by importing essentially mental categories into our analysis of the physical world. I would go further and assert that this way of thinking, for all its useful correctives to much of the naive physicalism and materialism pervading metaphysics, threatens to resuscitate the confused and confusing debates about final causes from several centuries ago, thereby undermining the proper revival of the concept of finality as it should be understood. What we should be comparing are not mental actualities and physical powers, but the mental and physical powers and how they are manifested. Both mental and physical powers possess finality understood as specific indifference. No power, be it mental or physical, can be had without restriction 
to a specific range of objects and indifference within that range. The key differencethe one overlooked in the debate at worst, confusedly appreciated at best-is that when a rational creature thinks a thought, thereby manifesting the power of thought, they do and must abstract - thereby displaying the finality possessed by the underlying power, which they manifest by the actual thought. But when a physical power manifests, the manifestation has no such correlate: it is wholly particularised or concretised, there being only one way, invariant across different circumstances (of time, place, and environment), in which the manifestation takes place.

Hence, to make a glib ${ }^{100}$ comparison of the form: ' $\mathrm{S}$ can think of $\mathrm{X}$ in this way rather than that' and 'Physical power $\mathrm{P}$ can have manifestation $\mathrm{M}$ in this way rather than that' is to miss everything that is important in this debate. The manifestation of the power of thought is always aspectual; there is no such correlate in the case of physical powers. Interestingly-briefly taking a broader perspective-this aspectuality is both a strength and a weakness of the rational animals that we humans are. It is a strength inasmuch as it is the source of reason itself and of the control over nature that reason allows. The aspectuality of abstraction enables focus, judgment, and inference- the ability to make connections unavailable to a non-rational creature. On the other hand, it is also a weakness inasmuch as we are forever condemned never to see anything in all of its aspects, either at a time or over time. Our finite intelligences must engage in ratiocination in order to arrive at any knowledge beyond the immediately perceptual and sensory precisely because we are unable to see all the aspects of anything. Being able to see all aspects means being able to see all connections. Since we cannot see all connections - whether within an object or between distinct objects-we have to reason in order to make the connections we cannot see, and this always in no more than a finite, piecemeal fashion. The best way of understanding this weakness is to contrast our minds with the mind of a being that did see all the aspects of everything. For such a being, all connections would be evident; there would be no connections to make, and hence no reasoning in which to engage. Such a being would not need to put two and two together to get four, as it were, because for such a being there would be nothing to put together in the first place.

\section{Conclusion}

I have argued that finality, at least when considering powers and their manifestations, is best understood by means of the concept of specific indifference. In the case of physical powers there is always restriction to a range of manifestations, coupled with some degree of indifference within the range as to the circumstances of manifestation. In the case of mental powers, thought is always restricted in its object, within which there is indifference as to how an object is thought of. The crucial difference is that the finality of thought involves abstraction, which gives freedom where there is none in the manifestation of a physical power. Whereas abstraction is something that rational thinkers $d o$, the finality of physical powers is something they merely have. The progress

100 I am not accusing any physical intentionalist of glibness; I am only suggesting that a superficially appealing analogy of this kind might motivate sympathy for the physical intentionalist viewpoint. 
in understanding provided by the idea of physical intentionality lies not in specious comparisons between the mind in the person and the 'mind in nature'. ${ }^{101}$ Rather, it resides in the long-discarded idea of finality that the contemporary analysis of powers has, inadvertently or not, succeeded in reviving.

With all of this in view, we can at least partially demystify physical intentionality. In the end it is no more nor less than a kind of finality. The same is true of mental intentionality. For a materialist, mental intentionality will be just a species of physical intentionality - the kind in which consciousness, or mental representation, plays an essential role. For anyone (such as myself) who thinks that the abstraction at the heart of mental finality cannot be explained in purely material terms, there will only be at best a partial overlap between mental and physical finality. Both will be genuine species of finality, but the physical will never be generic relative to the mental.

In any case, we have still only reached a point of partial demystification. The demystification lies in the removal of worries about 'spooky' panpsychist or animist implications of the kind that concern Mumford and other sceptics of physical finality. It lies also in the recognition that the pre-modern concept of finality has a metaphysically and scientifically respectable_-indeed ineliminable_place in our best account of reality. The partialness of the demystification, however, lies in the same fact - that the world contains irreducible finality, without which efficient causation itself cannot be explained. Should we rest content, along with Aristotle, in accepting a purely naturalistic account of this finality? In other words, is it enough to accept that finality is part of the very fabric of physical and mental reality? Or should we feel some of the discontent felt by the scholastics, in particular Aquinas, over the idea that this phenomenon of 'directedness' - the governance by final causes of all agency-might require no further explanation? Foundational questions such as these, already beginning to be addressed in contemporary metaphysics, ${ }^{102}$ demand further investigation. For the present, at least we have an answer to the simple question, 'Is there physical intentionality?'. It can be summarised by what Aquinas himself would have said if asked: 'Non proprie dictu, sed secundum quid'. ${ }^{103}$

Acknowledgements I am grateful to audiences at the National University of Singapore and the University of Oxford for comments received on earlier versions of this paper, and to two anonymous referees whose detailed critiques have resulted in significant improvements across the board.

Open Access This article is distributed under the terms of the Creative Commons Attribution 4.0 International License (http://creativecommons.org/licenses/by/4.0/), which permits unrestricted use, distribution, and reproduction in any medium, provided you give appropriate credit to the original author(s) and the source, provide a link to the Creative Commons license, and indicate if changes were made.

\section{References}

Anscombe, G. E. M. (1981/1974). "Whatever has a beginning of existence must have a cause": Hume's argument exposed. In The collected philosophical papers of G.E.M. Anscombe, Volume 1: From

101 To quote the title of Martin (2008).

102 For a very informative discussion, see Feser (2013).

103 'Not strictly speaking, but in a way.' 
Parmenides to Wittgenstein. Oxford: Basil Blackwell (1981). Originally published in Analysis, 34, 145-151 (1974).

Anscombe, G. E. M. (2002/1965). The intentionality of sensation: A grammatical feature. In A. Noë \& E. Thompson (Eds.), Vision and mind: Selected readings in the philosophy of perception (pp. 55-75). Cambridge, MA: Bradford Books/MIT Press. Originally published in R. J. Butler (Ed.), Analytical philosophy, second series (pp. 158-180). Oxford: Basil Blackwell (1965).

Aquinas St, T. (1920). Summa Theologica, Part 1, QQ.L-LXXIV, vol. 3 of The Summa Theologica of St Thomas Aquinas, literally translated by the Fathers of the English Dominican Province. London: Burns, Oates and Washbourne.

Armstrong, D. M. (1989). Universals: An opinionated introduction. Boulder, CO: Westview Press.

Armstrong, D. M., Martin, C. B., \& Place, U. T. (1996). In T. Crane (Ed.), Dispositions: A debate. London: Routledge.

Barker, S. (2013). The emperor's new metaphysics of powers. Mind, 122, 605-653.

Bird, A. (2001). Necessarily, salt dissolves in water. Analysis, 61, 267-274.

Bird, A. (2007). Nature's metaphysics: Laws and properties. Oxford: Clarendon Press.

Bird, A. (2010). Discovering the essences of natural kinds. In H. Beebee \& N. Sabarton-Leary (Eds.), The semantics and metaphysics of natural kinds (pp. 125-136). London: Routledge.

Brentano, F. (1995/1874). In O. Kraus \& L. L. McAlister (Eds.), Psychology from an empirical standpoint (A. C. Rancurello, D. B. Terrell, \& L. L. McAlister, Trans.). London: Routledge.

Buridan, J. (2001). Summulae de Dialectica (G. Klima, Trans.). New Haven: Yale University Press.

Burtt, E. A. (1925). The metaphysical foundations of modern physical science. London: Kegan Paul, Trench, Trubner \& Co., Ltd.

Chisholm, R. M. (1957). Perceiving: A philosophical study. Ithaca: Cornell University Press.

Chisholm, R. M. (1967). Intentionality. In P. Edwards (Ed.), Encyclopedia of philosophy (Vol. 4, pp. 201204). New York: Macmillan.

Feser, E. (2013). Between Aristotle and William Paley: Aquinas's fifth way. Nova et Vetera, 11, 707-749.

Hawley, K., \& Bird, A. (2011). What are natural kinds? Philosophical Perspectives, 25, 205-221.

Heil, J. (2003). From an ontological point of view. Oxford: Clarendon Press.

Lycan, W. G. (1969). On "Intentionality" and the psychological. American Philosophical Quarterly, 6, $305-311$.

Martin, C. B. (2008). The mind in nature. Oxford: Clarendon Press.

Martin, C. B., \& Pfeifer, K. (1986). Intentionality and the non-psychological. Philosophy and Phenomenological Research, 46, 531-554.

Mellor, D. H. (1991). In defence of dispositions. In his Matters of metaphysics. Cambridge: Cambridge University Press. Originally published in The Philosophical Review, 83, 157-181, 1974.

Molnar, G. (2003). In S. Mumford (Ed.), Powers: A study in metaphysics. Oxford: Oxford University Press.

Mumford, S. (1999). Intentionality and the physical: A new theory of disposition ascription. The Philosophical Quarterly, 49, 215-225.

Mumford, S. (2004). Laws in nature. London: Routledge.

Mumford, S., \& Anjum, R. L. (2011). Getting causes from powers. Oxford: Oxford University Press.

Murray, A. (1993). Intentionale in Thomas Aquinas. Accessed 15 January 2016 from http://www.cis. catholic.edu.au/Files/Murray-IntentionaleinAquinas.pdf.

Oderberg, D. S. (2011). Essence and properties. Erkenntnis, 75(2011), 85-111.

Oderberg, D. S. (2012). No potency without actuality: The case of graph theory. In T. Tahko (Ed.), Contemporary Aristotelian metaphysics. Cambridge: Cambridge University Press.

Osler, M. J. (1996). From immanent natures to nature as artifice: The reinterpretation of final causes in seventeenth-century natural philosophy. The Monist, 79, 388-407.

Place, U. T. (1996). Intentionality as the mark of the dispositional. Dialectica, 50, 91-120.

Place, U. T. (1999). Intentionality and the physical: A reply to Mumford. The Philosophical Quarterly, 49, 225-231.

Prior, E. W., Pargetter, R., \& Jackson, F. (1982). Three theses about dispositions. American Philosophical Quarterly, 19, 251-257.

Psillos, S. (2002). Salt does dissolve in water, but not necessarily. Analysis, 62, 255-257.

Searle, J. R. (1983). Intentionality: An essay in the philosophy of mind. Cambridge: Cambridge University Press.

Tugby, M. (2013). Platonic dispositionalism. Mind, 122, 451-480.

Vetter, B. (2013). Multi-track dispositions. The Philosophical Quarterly, 63, 330-352. 
Walton, D. (1990). Ignoring qualifications (secundum quid) as a subfallacy of hasty generalization. Logique et Analyse, 129-130, 113-154.

Wuellner, B. (1956). Summary of scholastic principles. Chicago: Loyola University Press; reprinted 2011 by Editiones Scholasticae. 